Miguel Morita Fernandes da Silva

\title{
Marcadores genéticos e inflamatórios na insuficiência cardíaca: o impacto do exercício físico
}

Tese apresentada à Faculdade de Medicina da Universidade de São Paulo para obtenção do título de Doutor em Ciências

Programa de Cardiologia

Orientador: Prof. Dr. Fernando Bacal

SÃo PAULO 
Miguel Morita Fernandes da Silva

\section{Marcadores genéticos e inflamatórios na insuficiência cardíaca: o impacto do exercício físico}

Tese apresentada à Faculdade de Medicina da Universidade de São Paulo para obtenção do título de Doutor em Ciências

Programa de Cardiologia

Orientador: Prof. Dr. Fernando Bacal

SÃo PAULO 


\section{Dados Internacionais de Catalogação na Publicação (CIP)}

Preparada pela Biblioteca da

Faculdade de Medicina da Universidade de São Paulo

Creprodução autorizada pelo autor

\section{Silva, Miguel Morita Fernandes da}

Marcadores genéticos e inflamatórios na insuficiência cardíaca : o impacto do exercício físico / Miguel Morita Fernandes da Silva. -- São Paulo, 2015.

Tese(doutorado)--Faculdade de Medicina da Universidade de São Paulo. Programa de Cardiologia.

Orientador: Fernando Bacal.

Descritores: 1.Exercício 2.Inflamação 3.Interleucina-6 4.Fator de necrose tumoral alfa 5.Galectina 3 6.Adiponectina 7.MicroRNAs 8.Insuficiência cardíaca 9.Tolerância ao exercício

USP/FM/DBD-458/15 


\section{Dedicatória}


A meus pais, Silvio e Keiko, cujo modo de ser, viver e ver o mundo serão sempre
minha inspiração.

Aos meus irmãos Fernando e Adriano, que sempre me ajudaram e tornaram tudo tão mais fácil.

A Clara e Betina, que me ensinam a cada dia o quão fascinante é uma descoberta.

A minha Renata, com quem compartilho cada pedaço desta estrada. 
Agradecimentos 
Aos pacientes que, em um gesto altruísta, contribuíram para melhorar o conhecimento médico, esperando reduzir o sofrimento alheio.

Ao meu orientador, Prof. Dr. Fernando Bacal, que acreditou em mim e abriu as portas para um novo mundo.

Ao meu coorientador, Prof. Dr. Guilherme Veiga Guimarães, por todo auxílio, suporte e ensinamentos, que tornaram possível a realização deste projeto.

Aos colegas Vagner Carvalho, Lais Cruz, Rafael Castro, Aline e Jean Roque por toda a dedicação e engajamento que foram determinantes neste estudo.

Aos amigos Lara, Carmen, Badu, Francisco, Maria do Rocio e Rafael, pelo suporte incondicional a tantas idas e vindas, sem o qual este trabalho jamais teria se realizado.

Aos cardiologistas Sandrigo Mangini, Fabiana Marcondes Braga, Luis Seguro, Monica Avila, Jefferson Vieira, Bruno Biseli e Marco Alves pelo apoio e companheirismo.

Aos Profs. Drs. Edimar Bocchi, Silvia Ayub, Paulo Chizzola, Victor Issa e Germano Souza pelo acolhimento e apoio.

Às funcionárias Ciça, Lourdes, Fatima e Sara do Núcleo de Insuficiência Cardíaca e a Fatima do Núcleo de Transplante pelo suporte especial nos momentos que eu mais precisava.

Aos amigos Odilson Silvestre e Wilson Nadruz, pelos conselhos e parceria inigualáveis.

Aos Prof. Drs. Protasio Lemos da Luz, Jose Rocha Faria, Lídia Zytynski e Marcio Sommer por terem me ajudado a seguir um novo caminho.

Ao Prof. Dr. Romeu Meneghelo, por todos seus ensinamentos na medicina, na ciência e na vida. 
Aos Prof. Dr. Jose Eduardo Krieger, Alexandre Pereira e a Noeli pela ajuda com o armazenamento das amostras.

Aos Prof. Dr. Edécio Cunha e Ludmila pelo auxílio na avaliação dos microRNAs.

Aos membros participantes da minha banca de qualificação, Profa. Dra. Ludhmila Abrahão Hajjar, Prof. Dr. Félix Ramires e Prof. Dr. Fabio Fernandes pelas sugestões que contribuíram para a finalização desta tese.

À Comissão de Pós-graduação e a Neusa Dini, Juliana Lattari Sobrinho e Tatiane Lago pela competência e profissionalismo ao fazerem parte de minha jornada e de tantos outros.

À Comissão Científica, especialmente ao Marcio, pelo auxílio em etapas críticas do projeto que foram fundamentais para sua concretização e por todo estímulo que proporcionam a pesquisa.

A todos aqueles que me ajudaram direta ou indiretamente e que pelo acaso não foram mencionados aqui, sintam-se também agradecidos.

À Fundação do Amparo à pesquisa do Estado de São Paulo (FAPESP), pela concessão do auxílio à pesquisa e apoio financeiro neste projeto.

Ao Conselho Nacional de Desenvolvimento Científico e Tecnológico, pela concessão da bolsa de doutorado, garantindo tempo protegido para a realização desse projeto. 
Epígrafe 
“Você pode nunca saber que resultados virão de suas ações, mas se não fizer nada, não existirão resultados." 


\section{Normalização adotada}

Esta tese está de acordo com as seguintes normas, em vigor no momento desta publicação:

Referências: adaptado de International Committee of Medical Journals Editors ( Vancouver).

Universidade de São Paulo. Faculdade de Medicina. Divisão de Biblioteca e Documentação. Guia de apresentação de dissertações, teses e monografias. Elaborado por Anneliese Carneiro da Cunha, Maria Julia de A.L. Freddi, Maria F. Crestana, Marinalva de Souza Aragão, Suely Campos Cardoso, Valéria Vilhena. $3^{\text {a }}$ ed. São Paulo: Divisão de Biblioteca e Documentação; 2011.

Abreviaturas dos títulos dos periódicos de acordo com List of Journals Indexed in Index Medicus. 


\section{Sumário}

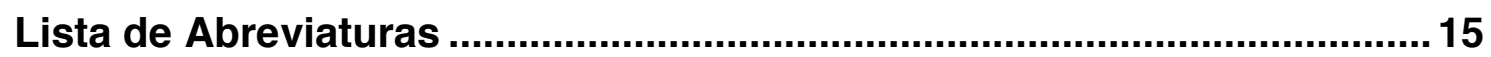



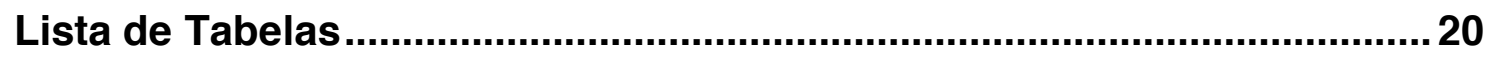

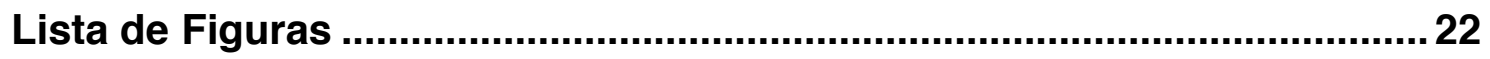

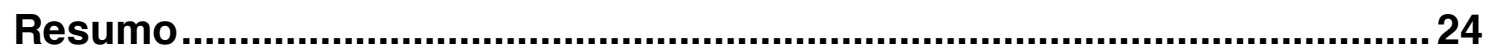



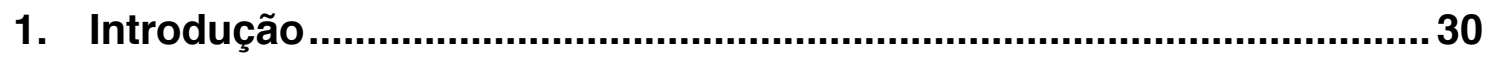

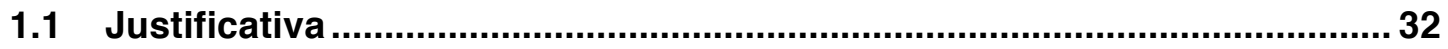

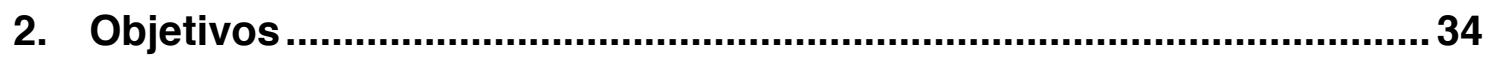

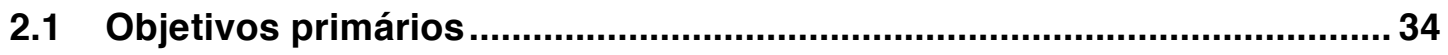

2.2 Objetivo secundário ........................................................................................ 34

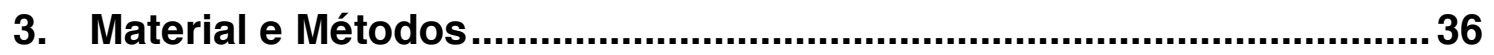

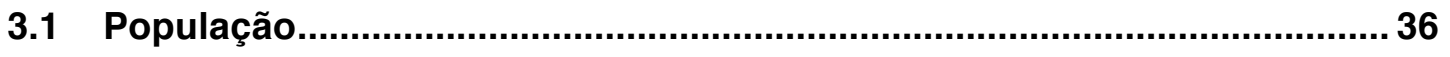

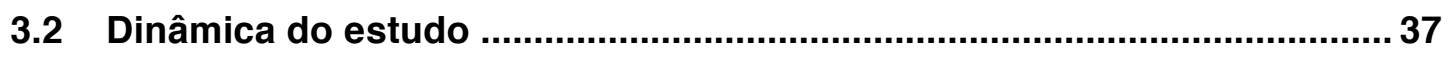

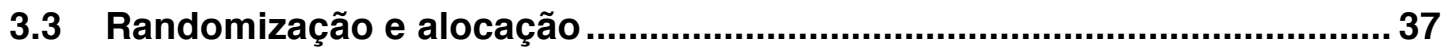

3.4 Teste de esforço cardiopulmonar............................................................. 37

3.5 Avaliação de atividade física na vida diária.................................................39

3.6 Avaliação da qualidade de vida ............................................................. 40

3.7 Dosagens sanguíneas............................................................................... 40

3.8. Programa de exercício supervisionado ..................................................... 44

3.9. Análise estatística ................................................................................... 45

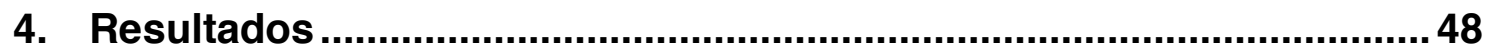

4.1. Características da amostra............................................................... 48

4.2. Teste de esforço cardiopulmonar....................................................51

4.3. Biomarcadores inflamatórios ................................................................... 53

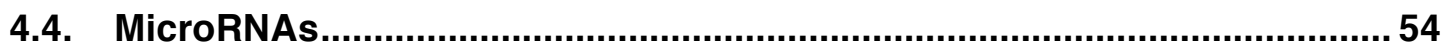






4.6. Preditores de resposta ao treinamento físico ......................................56

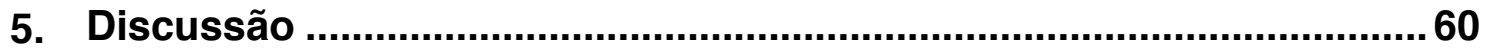

5.1. Efeitos do exercício nos biomarcadores inflamatórios.............................60 60

5.2. Efeito do exercício na qualidade de vida ................................................61

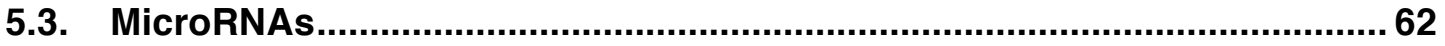

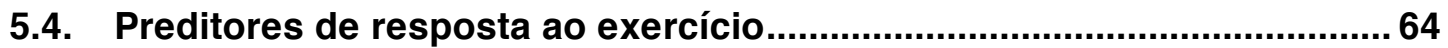

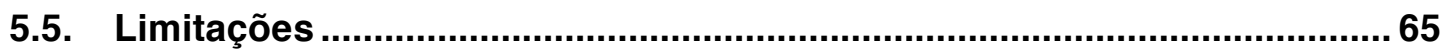

6. Conclusões ...................................................................................... 68

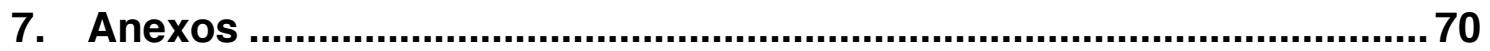

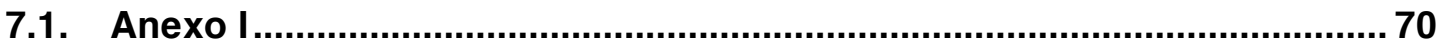

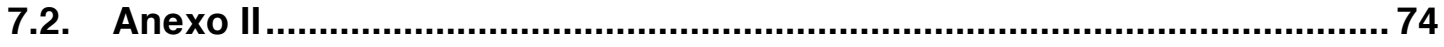

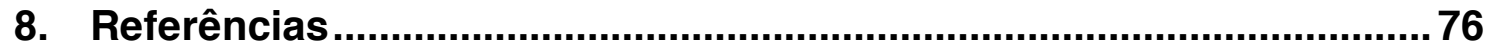




\section{Lista de abreviaturas}




\section{LISTA DE ABREVIATURAS}

\begin{tabular}{|c|c|}
\hline AFVD & Atividade física na vida diária \\
\hline ANOVA & Análise de variância \\
\hline BNP & Peptídeo natriurético tipo B \\
\hline BRA & Bloqueador do receptor da angiotensina II \\
\hline CAC & Células angiogênicas circulantes \\
\hline CAPPesq & Comissão de Ética para Análise de Projetos de Pesquisa \\
\hline Carga LA & Carga no limiar anaeróbico \\
\hline CMD & Concentração mínima detectável \\
\hline $\mathrm{cq}$ & quantification cycle \\
\hline $\mathrm{CV}$ & Coeficiente de variação \\
\hline$\Delta \mathrm{VO}_{2} / \Delta \mathrm{Carga}$ & Inclinação da relação do consumo de oxigênio pela carga durante o exercício \\
\hline EDTA & Ethylenediaminetetraacetic acid \\
\hline FAPESP & Fundação de Amparo à Pesquisa do Estado de São Paulo \\
\hline $\mathrm{FC}$ & Frequência cardíaca \\
\hline FEVE & Fração de ejeção do ventrículo esquerdo \\
\hline GEA & Gasto energético durante a atividade \\
\hline HCFMUSP & Hospital das Clínicas da Faculdade de Medicina da Universidade de São Paulo \\
\hline HF-ACTION & Heart Failure: A Controlled Trial Investigating Outcomes of Exercise Training \\
\hline IC & Insuficiência cardíaca \\
\hline IECA & Inibidor de enzima conversora de angiotensina \\
\hline IL-6 & Interleucina 6 \\
\hline IM & Intensidade do movimento durante a caminhada \\
\hline IMC & Índice de massa corpórea \\
\hline InCor & Instituto do Coração \\
\hline LA & Limiar anaeróbico \\
\hline Log-IL-6 & Interleucina-6 após conversão logarítmica \\
\hline MAP & Multi-analyte panels \\
\hline MLWHF & Minnesota Living With Heart Failure \\
\hline NYHA & New York Heart Association \\
\hline
\end{tabular}




\begin{tabular}{|c|c|}
\hline PA & Pressão arterial \\
\hline $\mathrm{PE}$ & Ficoeritrina \\
\hline $\mathrm{PET} \mathrm{CO}_{2}$ & Pressão parcial de dióxido de carbono \\
\hline $\mathrm{PET} \mathrm{O}_{2}$ & Pressão parcial de oxigênio no final da expiração \\
\hline Pulso $\mathrm{O}_{2}$ & Pulso de oxigênio \\
\hline PCR & Reação em cadeia polimerase \\
\hline RT-PCR & Reação em Cadeia da Polimerase em Tempo Real \\
\hline RER & Razão de trocas respiratórias \\
\hline RNA & Ácido ribonucleico \\
\hline RNAm & RNA mensageiro \\
\hline TECP & Teste de esforço cardiopulmonar \\
\hline TNF-alfa & Fator de necrose tumoral alfa \\
\hline $\mathrm{VCO}_{2}$ & Produção de dióxido de carbono \\
\hline $\mathrm{VE}$ & Ventilação \\
\hline${\mathrm{VE}-\mathrm{VCO}_{2} \text { slope }}$ & $\begin{array}{l}\text { Inclinação da relação da ventilação pela produção dióxido de carbono durante o } \\
\text { exercício }\end{array}$ \\
\hline $\mathrm{VE} / \mathrm{VO}_{2}$ & Equivalente ventilatório de oxigênio \\
\hline $\mathrm{VO}_{2}$ & Consumo de oxigênio \\
\hline $\mathrm{VO}_{2} \mathrm{LA}$ & Consumo de oxigênio no limiar anaeróbico \\
\hline $\mathrm{VO}_{2}$ pico & Consumo pico de oxigênio \\
\hline VP & Ventilação periódica \\
\hline
\end{tabular}




\section{Lista de símbolos}




\section{LISTA DE SÍMBOLOS}

\begin{tabular}{|c|c|}
\hline bpm & batimentos por minuto \\
\hline$\beta$ & beta \\
\hline g & gravidade; refere-se a aceleração devido a gravidade da Terra \\
\hline Kcal & quilocalorias \\
\hline $\min$ & minutos \\
\hline mcg.mL $L^{-1}$ & microgramas por mililitro \\
\hline $\mathrm{mg} \cdot \mathrm{dL}^{-1}$ & miligramas por decilitro \\
\hline $\mathrm{mL}$ & mililitros \\
\hline mL.bat ${ }^{-1}$ & mililitros por batimento \\
\hline $\mathrm{mL} \cdot \min ^{-1}$ & mililitros por minuto \\
\hline $\mathrm{mL} \cdot \mathrm{min}^{-1} \cdot \mathrm{W}^{-1}$ & mililitros por minuto por Watt \\
\hline $\mathrm{mL} \cdot \mathrm{kg}^{-1} \cdot \min ^{-1}$ & mililitros por quilograma por minuto \\
\hline ng. $\mathrm{mL}^{-1}$ & nanogramas por mililitro \\
\hline$p$ & valor-p \\
\hline pg.mL $L^{-1}$ & picogramas por mililitro \\
\hline Kg. $\mathrm{m}^{-2}$ & quilogramas por metro quadrado \\
\hline $\mathrm{s}$ & segundos \\
\hline $\mathrm{W}$ & Watts \\
\hline W. $\min ^{-1}$ & Watts por minuto \\
\hline$\mu \mathrm{L}$ & microlitros \\
\hline${ }^{\circ} \mathrm{C}$ & graus Celsius \\
\hline \pm & mais ou menos \\
\hline$<$ & menor \\
\hline$\leq$ & menor ou igual \\
\hline$\%$ & porcento \\
\hline
\end{tabular}




\section{Lista de tabelas}




\section{LISTA DE TABELAS}

Tabela 1: Características basais dos participantes

Tabela 2: Resultados do teste de esforço cardiopulmonar conforme o grupo

Tabela 3: Escore de qualidade de vida de acordo com o questionário Minnesota Living

With Heart Failure

Tabela 4: Associação entre as características basais e a mudança do consumo pico de oxigênio com exercício $(\mathrm{n}=26)$

Tabela 5: Análise de regressão multivariada predizendo a mudança do consumo pico de oxigênio com exercício $(n=26)$. 


\section{Lista de figuras}




\section{LISTA DE FIGURAS}

Figura 1: Fluxograma dos pacientes no estudo.

Figura 2: Níveis séricos de interleucina-6 após conversão (A), fator de necrose tumoral-alfa (B), adiponectina (C) e galectina-3 (D) antes e depois da intervenção de acordo com o grupo alocado

Figura 3: Mudança nos níveis séricos dos microRNAs miR-423-5p (A), miR-155 (B) e miR-221 (C) de acordo com intervenção realizada de acordo com o grupo alocado. 54 
Resumo 


\section{RESUMO}

FERNANDES MMF, Marcadores genéticos e inflamatórios na insuficiência cardíaca: o impacto do exercício físico [Tese]. São Paulo: Faculdade de Medicina, Universidade de São Paulo; 2015.

Introdução: $O$ exercício físico pode reverter o prejuízo funcional causado pela insuficiência cardíaca (IC). No entanto, os mecanismos implicados na melhora funcional e o efeito do exercício em outros biomarcadores de gravidade, incluindo microRNAs e marcadores de inflamação, são apenas parcialmente compreendidos.Objetivos: Avaliar o efeito do exercício nos níveis séricos da adiponectina, interleucina-6 (IL-6), fator de necrose tumoral alfa (TNF-alfa), galectina-3, microRNAs miR-423-5p, -221 e -155 em pacientes com IC. Analisar a associação entre estes biomarcadores e a melhora da capacidade funcional após 12 semanas de exercício em pacientes com IC. Métodos: Foram incluídos pacientes com IC, FEVE $\leq 40 \%$, terapia clínica otimizada e randomizados em três grupos: exercício intervalado, exercício contínuo ou controle. Foi realizado teste de esforço cardiopulmonar (TECP) e dosados os níveis séricos de adiponectina, IL-6, TNF-alfa, galectina-3, microRNAs miR-423-5p, -221 e -155 antes e após a intervenção, com duração de 12 semanas. Resultados: Quarenta pacientes, $49 \pm 7$ anos, 53\% homens, FEVE 30 $\pm 6 \%$, $25 \%$ com cardiopatia isquêmica foram incluídos na análise (intervalado-12, continuo-14, controle-14). O exercício, especialmente intervalado, aumentou o tempo de tolerância ao esforço no TECP em relação ao grupo controle (intervalado - $13 \pm 3$ min vs contínuo - $12 \pm 3$ min vs controle - $11 \pm 2 \min , p=0,034)$, mas não teve efeito no $\mathrm{VO}_{2}$ pico. Ambas modalidades de exercício, intervalado e contínuo, tiveram efeito neutro em todos os biomarcadores séricos dosados, incluindo os microRNAs. Os parâmetros basais associados com mudança na capacidade funcional foram o tempo de tolerância ao esforço no TECP e o nível sérico de IL-6. Na análise multivariada, somente o nível sérico de IL-6 (após conversão logarítmica) foi significativamente associado com mudança no $\mathrm{VO}_{2}$ pico com o exercício [Coeficiente $\beta=-0,35 \pm 0,11, p=0,005]$. Conclusões: Doze semanas de exercício aeróbico, tanto intervalado como contínuo, tiveram efeito neutro em biomarcadores de inflamação e fibrose e nos níveis circulantes dos microRNAs miR-423-5p, -221 e -155 em 
pacientes com IC. Além disso, níveis séricos elevados de IL-6 foram independente associados a ausência de resposta ao treinamento físico.

Descritores: exercício, inflamação, interleucina-6, fator de necrose tumoral alfa, galectina 3, adiponectina, MicroRNAs, insuficiência cardíaca, tolerância ao exercício. 
Abstract 


\begin{abstract}
SILVA MMF, Genetic and inflammatory markers in heart failure: the impact of exercise training [Thesis]. São Paulo: “Faculdade de Medicina, Universidade de São Paulo"; 2015.
\end{abstract}

Background: Exercise training can revert the functional impairment caused by heart failure (HF). Nevertheless, the mechanisms underlying the improvement in functional capacity and the effect of the exercise on other biomarkers of severity, including microRNAs and inflammatory biomarkers, are only partially understood. Aims: To evaluate the effect of exercise on serum levels of adiponectin, interleucina-6 (IL-6), tumor necrosis fator-alpha (TNF-alpha), galectina-3, microRNAs miR-423-5p, -221 and -155 in patients with HF. To assess the association between these biomarkers and improvement in functional capacity after 12 weeks of exercise in patients with HF. Methods: We included patients with HF, LVEF $\leq 40 \%$, under optimized clinical therapy, and randomized into three groups: interval exercise, continuous exercise and control. We performed cardiopulmonary exercise testing (CPET) and determined the serum levels of adiponectin, IL-6, TNF-alpha, galectina-3, microRNAs miR-423-5p, -221 and -155 before and after the intervention, which lasted 12

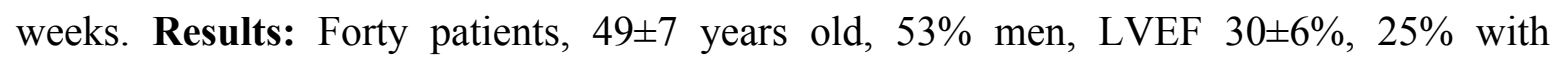
ischemic cardiomyopathy were included in the analysis (interval-12, continuous-14, control-14). The exercise, particularly the interval training, increased the CPET exercise time, when compared with the control group (interval - $13 \pm 3$ min vs continuous $-12 \pm 3$ min vs control - $11 \pm 2$ min, $p=0.034$ ), but had no effect on peak $\mathrm{VO}_{2}$. Both modalities of exercise, interval and continuous, had neutral effect on all analyzed serum biomarkers, including the microRNAs. Baseline parameters associated with change in functional capacity with exercise were CPET exercise time and IL-6 serum level. In multivariate analysis, only IL-6 serum level (log-transformed) was significantly associated with modification in peak $\mathrm{VO}_{2}$ with exercise $[\beta$ coefficient $=-0.35 \pm 0.11, \mathrm{p}=0.005$ ]

Conclusions: Twelve weeks of aerobic exercise, both interval and continuous, had neutral effect on the serum biomarkers of inflammation and fibrosis and the circulant microRNAs miR-423-5p, -221 e -155 in patients with HF. Besides, increased IL-6 serum levels at baseline were independently associated with lack of response to exercise training. 
Descriptors: exercise, inflammation, interleukin-6, tumor necrosis factor-alpha, galectin 3, adiponectin, MicroRNAs, heart failure, exercise tolerance. 


\section{INTRODUÇão}

A insuficiência cardíaca (IC) é uma síndrome clínica complexa que envolve o sistema cardiovascular, neuroendócrino, musculoesquelético e imune, ${ }^{1,2}$ e resulta em intolerância ao esforço. Embora tenha havido avanços no tratamento, muitos pacientes ainda persistem com estes sintomas e evoluem com morte precoce. ${ }^{3}$

$\mathrm{O}$ exercício físico pode reverter parte do prejuízo funcional causado pela $\mathrm{IC}^{4}$, resultando em melhor qualidade de vida. ${ }^{5}$ Além disso, a melhora da capacidade funcional com exercício está associada a maior sobrevida nestes pacientes. Foi demonstrado que um aumento em $6 \%$ no consumo pico de oxigênio $\left(\mathrm{VO}_{2}\right.$ pico) com o treinamento físico é preditor independente de melhor sobrevida na IC. ${ }^{6}$

Há diversos mecanismos implicados na melhora funcional, como alterações na função endotelial, na função autonômica, na função cardíaca e na expressão genética. Com relação a este último, o exercício pode modificar a expressão do ácido ribonucleico (RNA) mensageiro através de silenciamento gênico por microRNAs, uma variedade de RNA não codificador de proteína. Os microRNAs se ligam ao RNA mensageiro (RNAm)-alvo, causando sua degradação ou inibindo sua codificação proteica. ${ }^{7}$

Diversos microRNAs são secretados normalmente na circulação, e podem variar em resposta a injúria ou outras condições patológicas. ${ }^{8}$ Estes microRNAs circulantes são especialmente relevantes porque sua liberação no plasma não reflete apenas a eliminação do conteúdo celular causado por lesão inespecífica, mas representa um mecanismo chave pelo qual diversas funções celulares são moduladas em resposta ao estresse tecidual. ${ }^{9}$

Em indivíduos saudáveis, o exercício pode modificar os níveis de microRNAs circulantes, sendo potenciais mediadores fisiológicos da adaptação cardiovascular induzida pelo exercício. ${ }^{10,11}$ Em pacientes com IC, alguns microRNAs circulantes tem sua expressão aumentada em comparação com controles saudáveis. O microRNA miR-423-5p está elevado no plasma destes pacientes, sendo um candidato atrativo na investigação diagnóstica de IC. ${ }^{12}$ Além disso, os níveis plasmáticos do miR-423-5p podem indicar 
gravidade já que se associaram positivamente com o peptídeo natriurético tipo B (BNP) e com a classe funcional. ${ }^{12,13}$ Enquanto os microRNAs circulantes vem sendo estudados como potenciais biomarcadores de IC, não há dados que o exercício possa modificar sua expressão, fazendo retornar a níveis mais próximos dos indivíduos saudáveis.

A inflamação também pode estar implicada na resposta ao treinamento físico na IC, já que ela tem um papel importante na fisiopatologia e progressão da doença. ${ }^{14-17}$ Os níveis plasmáticos de citocinas pro-inflamatórias estão diretamente associados com a classe funcional, e a ativação imune parece contribuir para este prejuízo funcional. ${ }^{18,19} \mathrm{O}$ efeito do exercício físico na inflamação é ainda pouco compreendido. Estudos mostraram que o exercício físico agudo aumenta os níveis plasmáticos do fator de necrose tumoral alfa (TNF-alfa) e da interleucina-6 (IL-6). ${ }^{20}$ Por outro lado, as consequências a longo prazo de um programa de exercício físico (exercício físico crônico) são variadas, podendo manter ou até reduzir seus níveis circulantes. ${ }^{21,22}$ Recentemente, foi demonstrado que o treinamento físico também reduz a adiponectina, ${ }^{23}$ hormônio secretado pelo tecido adiposo que está envolvido na inflamação e associado a pior prognóstico na IC. ${ }^{24}$

Outro biomarcador que pode ajudar a compreender os mecanismos de resposta ao treinamento de pacientes com IC é a galectina-3, uma lecitina ligada a $\beta$-galactosídeo envolvida no desenvolvimento da fibrose cardíaca. ${ }^{25}$ Além de ser marcador prognóstico, ${ }^{26-}$ ${ }^{29}$ a galectina-3 parece predizer resposta a algumas modalidades de tratamento na IC. ${ }^{30,31}$ Em uma análise do estudo "Heart Failure: A Controlled Trial Investigating Outcomes of Exercise Training" (HF-ACTION), ${ }^{32}$ os pacientes que apresentaram o maior aumento no $\mathrm{VO}_{2}$ pico foram aqueles com menores níveis basais de galectina-3.

Tradicionalmente, o método utilizado para prescrição de exercício aeróbico para pacientes com IC, é de intensidade moderada com carga constante, ou seja, o treinamento contínuo. Alternativamente, o treinamento intervalado, que consiste em alternar a intensidade da carga em moderada e alta, tem sido demonstrada como método efetivo, seguro e bem tolerado em pacientes com IC. ${ }^{33,34}$ As repercussões de diferentes modalidades e intensidades de exercício nos níveis sanguíneos nos biomarcadores de fibrose e inflamação são ainda indefinidas. 
Haveria algum marcador especifico que identifica pacientes que podem responder ao exercício? $\mathrm{O}_{\mathrm{VO}_{2}}$ pico está associado a mortalidade não apenas quando medido isoladamente, mas a melhora com exercício indica maior sobrevida. ${ }^{6}$ Portanto, a identificação de biomarcadores que predizem a melhora do $\mathrm{VO}_{2}$ pico pode ajudar a encontrar subgrupos que potencialmente se beneficiam com o exercício, com aumento na sobrevida. Com isto, futuros estudos nesta área podem testar se o treinamento físico direcionado a estes subgrupos pode ser mais eficaz.

Além disso, o exercício físico, um movimento corporal planejado, estruturado e repetitivo executado com uma finalidade específica, pode ter um efeito ainda maior naqueles pacientes com maior restrição física no dia a dia. A atividade física na vida diária (AFVD), independentemente da realização formal de exercício, é fator prognóstico na IC. $^{35} \mathrm{O}$ treinamento físico na IC objetiva interromper um ciclo vicioso: o sintoma desencadeado pelo esforço leva a uma redução da AFVD, a qual resulta em menor tolerância ao esforço. Se seu impacto seria maior naqueles pacientes com menor AFVD, ainda é uma questão em aberto.

\subsection{Justificativa}

A evidência mais recente indica que o exercício físico não tem impacto na sobrevida de pacientes com IC. Enquanto os estudos com poder para avaliar mortalidade aplicaram exercício de moderada intensidade no modo contínuo, o exercício intervalado tem se mostrado promissor por trazer benefício superior em alguns desfechos substitutos

como a capacidade funcional. ${ }^{33} \mathrm{O}$ estudo do efeito de diferentes modalidades de exercício em biomarcadores inflamatórios e microRNAs, associados com a gravidade da doença, é relevante como precursor de grandes ensaios clínicos randomizados com poder para avaliar o impacto do exercício intervalado na sobrevida de pacientes com IC. 
Objetivos 


\section{OBJETIVOS}

\subsection{Objetivos primários}

Avaliar o efeito do exercício nos níveis séricos do TNF-alfa, da IL-6, da galectina-3, da adiponectina e dos microRNAs circulantes miR-155, miR-221 e miR-423-5p em pacientes com IC.

Avaliar a associação entre estes biomarcadores e a melhora da capacidade funcional após 12 semanas de exercício em pacientes com IC.

\subsection{Objetivo secundário}

Avaliar o efeito do exercício intervalado e contínuo na qualidade de vida relacionada a IC. 
Métodos 


\section{MAterial e Métodos}

\subsection{População}

Este estudo foi aprovado pela Fundação de Amparo à Pesquisa do Estado de São Paulo (FAPESP), processo número 2011/00640-4 e pela Comissão de Ética para Análise de Projetos de Pesquisa (CAPPesq) protocolo número 0157/10.

Os participantes do estudo foram selecionados a partir do ambulatório de IC do Instituto do Coração (InCor) do Hospital das Clínicas da Faculdade de Medicina da Universidade de São Paulo (HCFMUSP) entre maio de 2011 e abril de 2013. Nós incluímos pacientes com diagnóstico de IC estágio $\mathrm{C}$, fração de ejeção do ventrículo esquerdo (FEVE) menor ou igual a 40\%, idade entre 30 e 60 anos e sob terapia clínica otimizada por um mínimo de seis semanas. A função ventricular foi obtida em ecocardiograma transtorácico até 12 meses prévios a inclusão.

Os critérios de exclusão foram asma brônquica ou doença pulmonar obstrutiva crônica em uso de corticóide e/ou $\beta$-agonista inalatórios, IC classe funcional IV (New York Heart Association - NYHA), fibrilação atrial, arritmia ventricular complexa, portadores de marca-passo ou cardioversor/desfibrilador implantável, insuficiência renal crônica (creatinina maior que 2,5 mg.dL $\mathrm{dL}^{-1}$ ), insuficiência arterial periférica crônica, obesidade grau III, cirrose hepática, uso de drogas ilícitas, etilismo atual, prática regular de exercícios físicos, limitação física ou cognitiva para realizar exercícios, razão de trocas respiratórias (RER) pico menor que 1,00, procedimento invasivo programado, participação em outro estudo ou má adesão persistente ao tratamento. Durante o estudo, aqueles que não comparecessem por mais de 5 aulas consecutivas ou não cumprissem um mínimo de $70 \%$ do total de sessões previstas foram excluídos da análise final. 


\subsection{Dinâmica do estudo}

Os pacientes elegíveis eram abordados pelo medico assistente, que perguntava se eles estariam interessados em participar de um estudo envolvendo treinamento físico. $\mathrm{O}$ investigador explicava todos os procedimentos, riscos, benefícios do estudo e que sua participação era voluntária. Subsequentemente, o paciente lia o termo de consentimento livre e esclarecido e, quando de acordo, fornecia o consentimento escrito (Anexo I).

Em seguida, era realizada uma avaliação inicial para registro das características clinicas basais, incluindo medicações em uso, classe funcional e função ventricular. Os pacientes também preenchiam o questionário de qualidade de vida Minnesota Living With Heart Failure (MLWHF). Subsequentemente, eles eram submetidos a coleta de sangue, a medida da AFVD e ao teste de esforço cardiopulmonar. Após uma revisão dos critérios de inclusão e exclusão, os participantes eram randomizados em três grupos: grupo intervalado, grupo continuo e grupo controle. Após 3 meses de intervenção, os pacientes foram reavaliados e submetidos aos mesmos procedimentos prévios a randomização.

\subsection{Randomização e alocação}

Foi realizada randomização simples, utilizando-se envelopes em um saco plástico. Cada envelope, selado e opaco, continha o nome de um dos três grupos. Após cada alocação, o respectivo envelope era devolvido antes da próxima randomização, de forma que cada paciente tivesse a mesma chance de ser selecionado a um dos 3 grupos.

\subsection{Teste de esforço cardiopulmonar}

Os pacientes foram submetidos a teste de esforço cardiopulmonar (TECP) em cicloergômetro programável (Union, Brasil), utilizando protocolo em rampa em ambiente com temperatura controlada $\left(21^{\circ} \mathrm{C}\right.$ a $\left.23^{\circ} \mathrm{C}\right)$. O incremento da carga a uma razão de $5,10 \mathrm{ou}$ 15 W. min $^{-1}$ foi individualizado a partir da impressão clínica no TECP pré-intervenção e 
repetida no TECP pós-intervenção. Os pacientes foram orientados a realizar uma refeição leve pelo menos duas horas antes e a evitar o consumo de bebidas contendo cafeína no dia do exame.

Após dois minutos em repouso, em posição sentada, os pacientes foram encorajados a realizar exercício progressivo até limitação por sintomas. O ritmo cardíaco foi monitorizado por sistema de 12 derivações (Marquette series 2000, Marquette Electronics, Milwaukee, WI, EUA). A ventilação (VE), as concentrações de oxigênio e de dióxido de carbono foram medidas respiração à respiração (SensorMedics, modelo Vmax 229, Yorba linda, CA, EUA). A pressão arterial foi monitorizada pelo monitor multiparamétrico HP68S (Hewlett-Packard, EUA), empregando transdutor oscilométrico de pressão arterial HP M1008B (Hewlett-Packard, EUA). Os critérios de interrupção do esforço foram as mesmas descritas nas diretrizes brasileiras de teste ergométrico. ${ }^{36}$

O limiar anaeróbico (LA) foi determinado pelo métodos ventilatório e V-slope. O método ventilatório utiliza o menor valor do equivalente ventilatório de oxigênio $\left(\mathrm{VE} / \mathrm{VO}_{2}\right)$, acompanhado do menor valor da pressão parcial de oxigênio no final da expiração $\left(\mathrm{PET} \mathrm{O}_{2}\right)$. O V-slope utiliza o ponto de inflexão causado pela perda de linearidade da curva da produção de dióxido de carbono $\left(\mathrm{VCO}_{2}\right)$ pelo consumo de oxigênio $\left(\mathrm{VO}_{2}\right)$. O LA foi definido pela concordância em pelo menos duas das três variáveis (VE/ $/ \mathrm{VO}_{2}$, PET $\mathrm{O}_{2}$ e $\mathrm{V}$-slope). $\mathrm{O}$ ponto de compensação respiratória foi definido pelo menor valor do equivalente ventilatório do dióxido de carbono $\left(\mathrm{VE} / \mathrm{VCO}_{2}\right)$ acompanhado do maior valor da pressão parcial de dióxido de carbono $\left(\mathrm{PET} \mathrm{CO}_{2}\right)$. $\mathrm{O} \mathrm{VO}_{2}$ pico foi o maior valor atingido ao final do período de exercício. Os dados foram tabulados em média de 30 segundos. $\mathrm{O} \mathrm{VO}_{2}$ máximo predito foi calculado a partir da idade, sexo, peso e altura segundo Wasserman et al. ${ }^{37}$ Os valores do $\mathrm{VO}_{2}$ pico são apresentados em $\mathrm{mL} \cdot \mathrm{kg}^{-1} \cdot \mathrm{min}^{-1} \mathrm{e}$ em $\%$ do máximo predito.

$\mathrm{O} \mathrm{VE}-\mathrm{VCO}_{2}$ slope foi determinado a partir da relação da $\mathrm{VE}$ pela $\mathrm{VCO}_{2}$ durante todo o período de exercício, como descrito previamente. ${ }^{38}$ A relação do $\mathrm{VO}_{2}$ pela carga $\left(\Delta \mathrm{VO}_{2} / \Delta \mathrm{Carga}\right)$ foi obtida de modo semelhante, utilizando-se o fator multiplicativo da equação de regressão linear entre $\mathrm{VO}_{2}\left(\mathrm{~mL} \cdot \mathrm{min}^{-1}\right)$ e carga (Watts-W) e expressa em 
$\mathrm{mL} \cdot \mathrm{min}^{-1} \cdot \mathrm{W}^{-1}$. O pulso de oxigênio (pulso $\mathrm{O}_{2}$ ) foi calculado pela divisão do $\mathrm{VO}_{2}(\mathrm{~mL}$.min

$\left.{ }^{1}\right)$ pela frequência cardíaca (FC) em batimentos por minuto (bpm).

A presença de ventilação periódica foi determinada conforme Leite et al: ${ }^{39}$ 1) três ou mais oscilações regulares (claramente discerníveis de artefato dos dados); 2) regularidade, dada pelo desvio padrão da duração de três ciclos consecutivos (tempo entre o nadir de dois ciclos) dentro de $20 \%$ da média, 3) amplitude média mínima da oscilação na VE de 5 litros (valor pico menos o ponto médio entre o nadir dos dois ciclos adjacentes).

\subsection{Avaliação de atividade física na vida diária}

A AFVD foi avaliada a partir de acelerômetro triaxial digital Dynaport MoveMonitor (McRoberts, Holanda), validado previamente. ${ }^{40}$ Este dispositivo mede $85 \mathrm{x}$ 58 x 11,5 mm, pesa 55 gramas e possui uma bateria de lítio que permite medir até sete dias consecutivos. Ele possui três sensores sísmicos dispostos ortogonalmente (anteroposterior, lateral-medial e longitudinal) com uma escala adaptável de \pm 2 g(resolução de 0,001 g) ou \pm 6 g(resolução de 0,003 g). Os dados obtidos eram armazenados em um cartão de memória microSD e enviados para http://www.mcroberts.nl, do qual retornavam em um arquivo .csv e em dois relatórios: atividade física e gasto energético.

O procedimento decorria da seguinte maneira: incialmente, o dispositivo era programado para iniciar a medida no período da manhã (entre 8:00 e 11:00) com duração de 24 horas. $\mathrm{O}$ acelerômetro era posicionado na região lombar, aproximadamente na altura de L2, e fixo com uma cinta de velcro. Todos os pacientes foram orientados a retirar o dispositivo apenas para o banho e a manter suas atividades habituais durante a medida.

Foram registrados o número de passos por dia, o tempo gasto em minutos e a intensidade do movimento (IM) em $\mathrm{g}\left(1 \mathrm{~g}=9,82 \mathrm{~m} \cdot \mathrm{s}^{-2}\right)$ durante a caminhada, o tempo sedentário (\%) e o gasto energético durante a atividade (GEA). O tempo sedentário se refere ao percentual de tempo em que o indivíduo permanece sentado ou deitado durante 
um dia. O GEA foi estimado à partir da IM em cada categoria por método previamente validado. $^{41,42}$

\subsection{Avaliação da qualidade de vida}

A qualidade de vida relacionada a saúde foi avaliada através de questionário específico para pacientes com IC, o questionário MLWHF (anexo II), na versão traduzida

para o português, previamente validada. ${ }^{43,44} \mathrm{O}$ questionário contém 21 questões e o paciente devia responder o quanto a IC impediu que vivesse da maneira como gostaria durante as quatro semanas anteriores. Os pacientes respondiam em uma escala de 0 a 5 , onde 0 indicava que não impediu ou não se aplica e 5 indicava que impediu muitíssimo. A somatória simples das 21 respostas formavam o escore total, com maiores valores indicando pior a qualidade de vida. Adicionalmente, um subgrupo de questões correspondia a um escore de dimensão física (itens $2,3,4,5,6,7,12,13$ ), por estarem relacionadas a sintomas como dispnéia e fadiga, e outro subgrupo a um escore de dimensão emocional (itens 17, 18, 19, 20, 21).

\subsection{Dosagens sanguíneas}

\subsubsection{Coleta de sangue}

As amostras de sangue foram obtidas através de venopunção após 20 minutos de repouso e jejum de 8 horas. Todos foram orientados a não realizar exercícios 24 horas antes. O sangue periférico foi coletado em três tubos de $3 \mathrm{~mL}$ : dois deles sem anticoagulante e o outro contendo Ethylenediaminetetraacetic acid (EDTA). Em seguida, foram submetidos à centrifugação sob força de $2000 \mathrm{~g}$ a $4^{\circ} \mathrm{C}$ durante 10 minutos. $\mathrm{O}$ sobrenadante (plasma ou soro) foi transferido para microtubos RNase/DNase-free de 1,5mL e armazenado em freezer $-70^{\circ} \mathrm{C}$ até o momento das análises. 


\subsubsection{Biomarcadores inflamatórios}

Após todos os pacientes completarem o estudo, foram determinados os níveis séricos do TNF-alfa, da IL-6, da adiponectina e da galectina-3 através de kits Milliplex® MAP (multi-analyte panels) usando tecnologia Luminex ${ }^{\mathrm{TM}}$ xMAP (EMD Millipore Coorporation, Alemanha).

O princípio da tecnologia Luminex ${ }^{\mathrm{TM}} x M A P$ utiliza um processo que envolve microesferas, fundamentado na técnica de imunoensaio. Cada uma destas microesferas é coberta com um anticorpo específico e pode ser identificada através de um código de cores. Após o analito (biomarcador) ser capturado pelos anticorpos localizados na superfície das microesferas, um anticorpo de detecção biotinilado é introduzido ligado a uma molécula de reporte - a ficoeritrina (PE). Processadores de sinal digital de alta velocidade identificam cada microesfera e fazem a leitura baseado no sinal fluorescente da PE.

Os procedimentos foram realizados de acordo com as instruções do fabricante por um laboratório externo (Genese Produtos Diagnósticos LTDA), que não tinha conhecimento a que grupo o paciente foi alocado. Kits específicos para cada análise foram usados: Human Circulating Cancer Biomarker Magnetic Bead panel 3 kit (HCCBP3MAG58K) para galectina-3 [concentração mínima detectável $(\mathrm{CMD})=0,005$ ng. $\mathrm{mL}^{-1}$, coeficiente de variação intra-ensaio (CV intra-ensaio) $=5 \%, \mathrm{CV}$ inter-ensaio $=13 \%]$; Human Adipokine Magnetic Bead Panel 2 kit (HADK2MAG-61K) para IL-6 [CMD = 0,2 pg.mL $\mathrm{mL}^{-1}, \mathrm{CV}$ intra-ensaio $=1 \%, \mathrm{CV}$ inter-ensaio $=10 \%$ ] e para TNF-alfa $[\mathrm{CMD}=0,3$

pg. $\mathrm{mL}^{-1}, \mathrm{CV}$ intra-ensaio $=3 \%, \mathrm{CV}$ inter-ensaio $\left.=19 \%\right]$; Human Adipokine Magnetic Bead Panel 1 kit (HADK1MAG-61K) para adiponectina $\left[\mathrm{CMD}=11 \mathrm{pg} \cdot \mathrm{mL}^{-1}, \mathrm{CV}\right.$ intra-ensaio $=$ $2 \%, \mathrm{CV}$ inter-ensaio $=10 \%$ ]. Os resultados foram calculados, usando o MagPix - Software $x$ Ponent/Analyst versão 4.2 . 


\subsubsection{MicroRNAs}

\subsubsection{Seleção dos MicroRNAs}

Nós selecionamos três microRNAs circulantes baseado em sua relevância como biomarcador na IC, resposta ao exercício ou que estivessem implicados em processos celulares adaptativos ao exercício. Desta maneira, nós escolhemos os microRNAs miR423-5p, apontado como potencial biomarcador diagnóstico e prognóstico da IC; ${ }^{12,13} \mathrm{o}$ miR221, envolvido na angiogênese, ${ }^{45,46}$ e que aumenta com treinamento físico em indivíduos saudáveis; ${ }^{10}$ e o miR-155, implicado na inflamação ${ }^{47}$ e no sistema renina-angiotensina. ${ }^{48}$

\subsubsection{Extração de RNA}

Após retiradas do freezer $-70^{\circ} \mathrm{C}$, as amostras foram equilibradas a temperatura ambiente e submetidas a extração de RNA extracelular por meio do kit miRNeasy Serum/Plasma (Qiagen, Alemanha) de acordo com o protocolo descrito pelo fabricante. Resumidamente, $1 \mathrm{~mL}$ da solução QIAZOL foi adicionado à $0,2 \mathrm{~mL}$ de plasma sanguíneo, sendo em seguida homogeneizado vigorosamente em vortex por $15 \mathrm{~s}$ e incubado por 05 min a temperatura ambiente para promover a dissociação dos complexos nucleoproteicos. Após incubação, $3 \mu \mathrm{l}$ do miR-39 sintético de Caenorhabditis elegans (cel-miR-39; QIAGEN) na concentração de $1,6 \times 10^{8} / \mu \mathrm{L}$ foram adicionados como controle "spike-in" para eficiência da

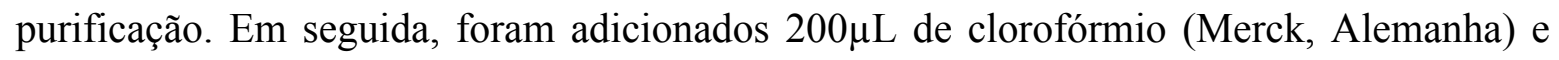
homogeneizado vigorosamente por 30s seguido por 5 min de incubação à temperatura ambiente. As amostras foram então submetidas à centrifugação sob força de $14.000 \mathrm{~g} \mathrm{a} 4^{\circ} \mathrm{C}$ por 20 min para a separação das fases aquosa (acima) e orgânica (abaixo). A fase aquosa foi então transferida para outro microtubo de $1,5 \mathrm{~mL}$ onde foi adicionado 1,5 volumes de etanol 100\% (Merck, Alemanha) para a precipitação do RNA total. A purificação do RNA total extraído foi realizado por meio das colunas providas pelo kit miRNeasy Serum/Plasma. O RNA final foi eluído das colunas em $14 \mu \mathrm{L}$ de água RNase-free também provido pelo kit. 


\subsubsection{Reação de transcrição reversa}

Para a técnica da Reação em Cadeia da Polimerase (PCR), passível de analisar apenas moléculas de DNA, as amostras de RNA extraídas foram convertidas em DNA complementar (cDNA) por meio da reação de transcrição reversa. Para este propósito foi utilizado o kit TaqMan ${ }^{\circledR}$ MicroRNA Reverse Transcription (Life Technologies, USA) combinado com oligonucleotídeos específicos para cada microRNA (miR-155, miR-221 e miR-423-5p providos pelo kit TaqMan ${ }^{\circledR}$ MicroRNA Assays - Life Technologies, USA). Os oligonucleotídeos utilizados foram stem-loop específicos, o que reduz a hibridização com os pri- e pre-miRNAs, aumentando assim a especificidade do ensaio.

\subsubsection{Quantificação relativa dos níveis plasmáticos de microRNAs}

A quantificação relativa dos níveis de expressão dos microRNAs foi mensurada por meio da técnica de Reação em Cadeia da Polimerase em Tempo Real (RT-PCR) utilizando o kit TaqMan ${ }^{\circledR}$ MicroRNA Assays. As reações foram otimizadas com o auxílio do kit TaqMan ${ }^{\circledR}$ Universal PCR Master Mix, AmpErase ${ }^{\circledR}$ UNG (Life Technologies, USA) e finalmente processados na plataforma StepOnePlus ${ }^{T M}$ Real-Time PCR Systems (Life Technologies, USA). Os dados foram obtidos em Cq (quantification cycle), que é o número de ciclos necessários para obter-se sinal de fluorescência acima do limiar padrão (10 desvios-padrão acima da fluorescência média do ciclo basal). Portanto, o número de cópias do microRNA e o Cq são inversamente relacionados por um fator logarítmico na base 2, onde a redução em $1 \mathrm{Cq}$ representa um aumento em 2 vezes no número de cópias. As análises foram realizadas em triplicata e a média dos três resultados foi considerada o $\mathrm{Cq}$ para a respectiva amostra. Subsequentemente, o $\mathrm{Cq}$ foi normalizado para o controle sintético "spike-in" conforme a equação abaixo ${ }^{49}$ :

$\mathrm{Cq}_{\text {normalizado }}=\mathrm{Cq}_{\text {obs }}-\left(\mathrm{Cq}_{\text {controle }}-\mathrm{Cq}_{\text {mediana }}\right)$

Onde o $\mathrm{Cq}_{\text {obs }}$ é o obtido para o microRNA em questão, $\mathrm{Cq}_{\text {controle }}$ refere-se ao controle sintético cel-miR-39 para a mesma amostra e $\mathrm{Cq}_{\text {mediana }}$ é a mediana dos resultados do controle sintético de todos pacientes em cada período (portanto uma mediana para antes 
e outra para após a intervenção). Os resultados da expressão de cada microRNA serão aqui

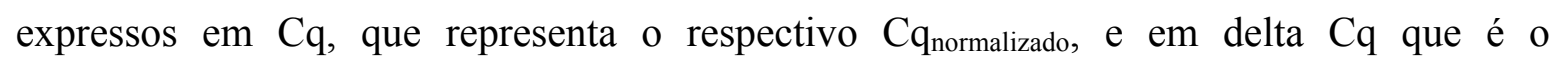
$\mathrm{Cq}_{\text {normalizado }}$ após menos o $\mathrm{Cq}_{\text {normalizado antes da intervenção. }}$

\subsubsection{Medidas para controle de contaminação}

Para a realização do estudo, processos que objetivam a minimização dos riscos de contaminação foram aplicados: utilização de reagentes de lote controlado e em alíquotas para evitar diversos ciclos de congelação e descongelação; todos os materiais utilizados foram de natureza RNase/DNase-free e manipulados em cabines de fluxo laminar livres de amplicons previamente tratadas com RNase Away (Invitrogen, USA). O uso de kits comerciais foi adotado para reduzir ao máximo o número de manipulações das amostras e diminuindo a chance de erro e repetições.

\subsection{Programa de exercício supervisionado}

Os pacientes randomizados para os grupos intervalado e contínuo foram submetidos a 12 semanas de treinamento aeróbico supervisionado, com três sessões de exercícios supervisionados por semana, duração de 50 minutos cada. O exercício foi realizado em bicicleta estacionária, iniciando com 5 minutos de aquecimento, 30 minutos de estímulo e 5 minutos de desaquecimento, completando um total de 40 minutos. Adicionalmente, os pacientes realizavam 5 minutos de alongamento de membros inferiores e superiores antes e após o exercício. Todos os participantes foram monitorizados com frequencímetro e escala subjetiva de esforço de Borg (7-20) durante a sessão. O exercício era interrompido caso o paciente apresentasse dor precordial, tonturas, náuseas, bradicardia, síncope, pré-síncope ou qualquer sintoma/sinal clinicamente relevante. 


\subsubsection{Treinamento aeróbico intervalado}

Pacientes randomizados para o grupo intervalado realizavam a fase de estímulo aeróbico intercalando 1 minuto na $\mathrm{FC}$ do ponto de compensação respiratória com 2 minutos na FC do LA.

\subsubsection{Treinamento aeróbico contínuo}

Pacientes randomizados para o grupo contínuo realizavam a fase de estímulo na zona alvo. A zona alvo foi determinada pela média aritmética das FC do LA e do ponto de compensação respiratória, podendo variar 4 bpm para mais ou para menos.

\subsection{Análise estatística}

O tamanho da amostra foi calculado para detectar uma diferença de $2,0 \mathrm{~mL} . \mathrm{kg}^{-}$ ${ }^{1}$. $\mathrm{min}^{-1}$ no $\mathrm{VO}_{2}$ pico entre 2 dos 3 grupos. ${ }^{6,33}$ Assim, assumindo-se erro alfa de $5 \%$ ajustado pelo método de Bonferroni e poder de $80 \%$, o tamanho mínimo da amostra foi de 12 pacientes em cada grupo. As análises foram realizadas usando Stata versão 13.1 (Stata Corp., College Station, Tx, EUA).

A normalidade da distribuição das variáveis contínuas em cada grupo foi verificada com o teste de Shapiro-Wilk. Elas foram apresentadas em média \pm desvio padrão ou mediana (25 percentil, 75 percentil) conforme aplicável. A IL-6 apresentou distribuição normal após transformação logarítmica, sendo por isso testada a partir dos dados transformados. Os três grupos foram comparados utilizando análise de variância (ANOVA), se distribuição normal, ou o teste de Kruskal-Wallis em caso contrário. Se encontrada diferença significativa, comparações de grupos pareados foi realizada com teste $\mathrm{T}$, ou Wilcoxon se não normal, e ajuste pelo método de Bonferroni. O teste do exato de Fisher foi usado para comparar as proporções das variáveis discretas. 
Em seguida, nós verificamos quais variáveis basais (antes da intervenção) estavam associados a melhora da capacidade funcional com o treinamento físico. Para isso, nós realizamos regressão linear univariada com a mudança no $\mathrm{VO}_{2}$ pico (\% predito) com exercício como variável dependente. A mudança no $\mathrm{VO}_{2}$ pico (\% predito) com o exercício, excluindo portanto o grupo controle, foi calculada pela diferença entre o $\mathrm{VO}_{2}$ pico (\% predito) pós menos o pré e apresentava distribuição normal. As variáveis cujo valor de $p$ foi menor que 0,10 foram incluídos em modelo de regressão linear multivariada e considerados preditores independentes se $p$ menor que 0,05 . 
Resultados 


\section{Resultados}

\subsection{Características da amostra}

Foram avaliados 602 pacientes durante o período de inclusão e 52 foram randomizados para cada um dos três grupos. Doze pacientes não completaram o estudo: nove desistiram por razões não relacionadas ao quadro clínico; dois foram internados por IC descompensada e um paciente do grupo controle não foi encontrado para reavaliação. $\mathrm{O}$ fluxograma dos pacientes no estudo está resumido na figura 1.

Um paciente do grupo contínuo foi a óbito por quadro infeccioso e não foi submetido a medida da AFVD após o treinamento. Como tinha realizado todos os outros exames da reavaliação, foi incluído na análise. 


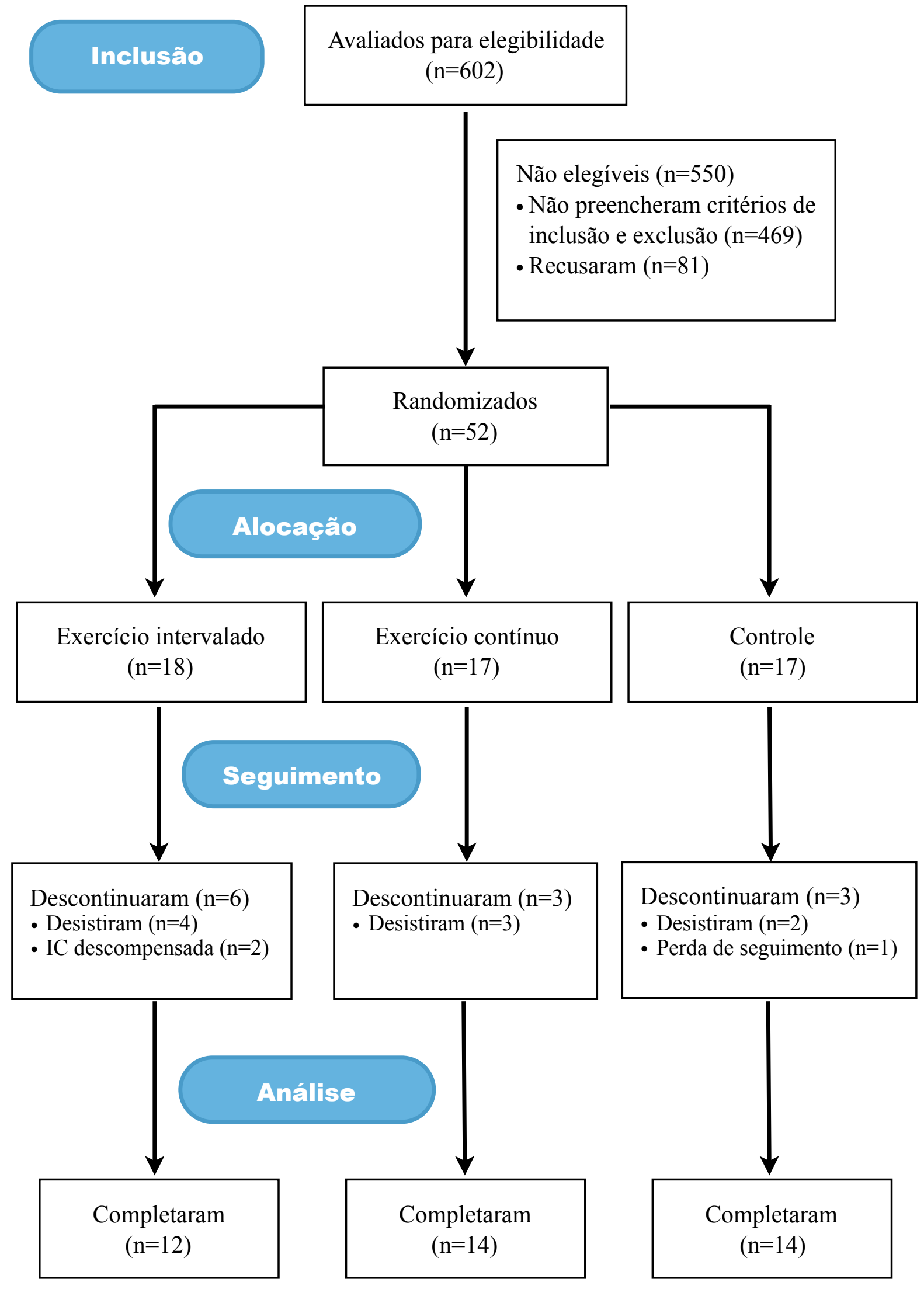

Figura 1: Fluxograma dos pacientes do estudo

* IC - insuficiência cardíaca 
A tabela 1 mostra as características basais dos participantes por grupo. Os três grupos eram semelhantes quanto à idade, índice de massa corpórea (IMC), sexo, FEVE, etiologia da IC, fatores de risco cardiovascular e tratamento medicamentoso.

Tabela 1: Características basais dos participantes

\begin{tabular}{|c|c|c|c|c|}
\hline Variável & $\begin{array}{c}\text { Intervalado } \\
\mathrm{n}=12\end{array}$ & $\begin{array}{c}\text { Contínuo } \\
\mathbf{n}=14\end{array}$ & $\begin{array}{c}\text { Controle } \\
n=14 \\
\end{array}$ & $p$ \\
\hline Idade, anos & $52 \pm 5$ & $50 \pm 9$ & $47 \pm 6$ & 0,15 \\
\hline Sexo masculino, n (\%) & $6(50)$ & $7(50)$ & $8(57)$ & 0,91 \\
\hline Raça branca, n (\%) & $8(67)$ & $10(71)$ & $11(79)$ & 0,79 \\
\hline Peso, Kg & $78 \pm 16$ & $79 \pm 17$ & $76 \pm 9$ & 0,84 \\
\hline IMC, Kg.m ${ }^{-2}$ & $28 \pm 4$ & $29 \pm 5$ & $28 \pm 4$ & 0,75 \\
\hline FEVE, \% & $30 \pm 7$ & $29 \pm 6$ & $29 \pm 6$ & 0,81 \\
\hline Hipertensão arterial, n (\%) & $6(50)$ & $8(57)$ & $6(43)$ & 0,75 \\
\hline Diabete melito, n (\%) & $0(0)$ & $5(36)$ & $3(21)$ & 0,08 \\
\hline Tabagismo atual, n (\%) & $2(17)$ & $0(0)$ & $1(7)$ & 0,27 \\
\hline Etiologia isquêmica, n (\%) & $4(33)$ & $4(29)$ & $2(14)$ & 0,50 \\
\hline Classe funcional, n (\%) & & & & 0,42 \\
\hline $\mathbf{I}$ & $1(8)$ & $4(29)$ & $3(21)$ & \\
\hline II & $6(50)$ & $7(50)$ & $4(29)$ & \\
\hline III & $5(42)$ & $3(21)$ & $7(50)$ & \\
\hline PA sistólica, mmHg & $102 \pm 15$ & $114 \pm 19$ & $102 \pm 11$ & 0,06 \\
\hline PA diastólica, mmHg & $57 \pm 11$ & $63 \pm 14$ & $58 \pm 7$ & 0,30 \\
\hline \multicolumn{5}{|l|}{ Medicações, n (\%) } \\
\hline IECA ou BRA & $12(100)$ & $14(100)$ & $14(100)$ & NA \\
\hline Betabloqueador & $12(100)$ & $14(100)$ & $14(100)$ & NA \\
\hline Carvedilol, dose em mg* & $62[50,100]$ & $50[50,75]$ & $50[50,100]$ & 0,90 \\
\hline Bloqueador aldosterona & $9(75)$ & $8(57)$ & $10(71)$ & 0,58 \\
\hline Digital & $4(33)$ & $3(21)$ & $6(43)$ & 0,48 \\
\hline
\end{tabular}

IMC - índice de massa corpórea; FEVE - fração de ejeção do ventrículo esquerdo, PA - pressão arterial; IECA - inibidor da enzima conversora de angiotensina; BRA - bloqueador do receptor da angiotensina II *Trinta e nove pacientes estavam em uso de carvedilol. 


\subsection{Teste de esforço cardiopulmonar}

Na avaliação basal, os três grupos não diferiam quanto aos parâmetros observados no TECP (tabela 2). Após a intervenção, observamos que o exercício, particularmente o intervalado, melhorou significativamente o tempo de tolerância ao esforço no TECP em relação ao grupo controle (tabela 2). Não houve diferença significativa nos outros parâmetros do TECP, incluindo $\mathrm{VO}_{2}$ pico ou carga no pico do esforço, assim como nas outras variáveis prognósticas, incluindo $\mathrm{VO}_{2}$ no $\mathrm{LA}$, o $\mathrm{VE}-\mathrm{VCO}_{2}$ slope e a ventilação periódica. Vale ressaltar que o RER pico foi semelhante entre os três grupos. 
Tabela 2: Resultados do teste de esforço cardiopulmonar conforme o grupo

\begin{tabular}{|c|c|c|c|c|c|c|}
\hline \multirow[b]{2}{*}{ Parâmetro } & \multicolumn{2}{|c|}{ Intervalado $(n=12)$} & \multicolumn{2}{|c|}{ Contínuo $(n=14)$} & \multicolumn{2}{|c|}{ Controle $(n=14)$} \\
\hline & Basal & 12 semanas & Basal & 12 semanas & Basal & 12 semanas \\
\hline Tempo, min & $10 \pm 2$ & $13 \pm 3^{* a}$ & $10 \pm 2$ & $12 \pm 3^{*}$ & $11 \pm 2$ & $11 \pm 2^{* \mathrm{a}}$ \\
\hline RER pico & $\begin{array}{c}1,09 \\
{[1,04,1,15]}\end{array}$ & $\begin{array}{c}1,16 \\
{[1,10,1,22]}\end{array}$ & $\begin{array}{c}1,15 \\
{[1,11,1,18]}\end{array}$ & $\begin{array}{c}1,18 \\
{[1,13,1,42]}\end{array}$ & $\begin{array}{c}1,11 \\
{[1,05,1,20]}\end{array}$ & $\begin{array}{c}1,14 \\
{[1,09,1,18]}\end{array}$ \\
\hline FC basal, bpm & $69 \pm 9$ & $71 \pm 8$ & $71 \pm 11$ & $70 \pm 10$ & $77 \pm 9$ & $75 \pm 10$ \\
\hline FC pico, bpm & $111 \pm 18$ & $126 \pm 21$ & $117 \pm 23$ & $121 \pm 19$ & $114 \pm 18$ & $118 \pm 22$ \\
\hline $\mathrm{VO}_{2}$ pico, $\mathrm{mL} \cdot \mathrm{kg}^{-1} \cdot \mathrm{min}^{-2}$ & $\begin{array}{c}12,9 \\
{[11,6,17,4]}\end{array}$ & $\begin{array}{c}15,4 \\
{[13,4,20,0]}\end{array}$ & $\begin{array}{c}13,8 \\
{[12,5,15,8]}\end{array}$ & $\begin{array}{c}15,2 \\
{[11,8,17,1]}\end{array}$ & $\begin{array}{c}13,8 \\
{[11,8,16,6]}\end{array}$ & $\begin{array}{c}14,4 \\
{[11,9,15,9]}\end{array}$ \\
\hline $\mathrm{VO}_{2}$ pico, \% & $\begin{array}{c}56 \\
{[50,63]}\end{array}$ & $\begin{array}{c}63 \\
{[57,80]}\end{array}$ & $\begin{array}{c}61 \\
{[47,74]}\end{array}$ & {$[53,78]$} & $\begin{array}{c}53 \\
{[40,72]}\end{array}$ & $\begin{array}{c}58 \\
{[43,68]}\end{array}$ \\
\hline Pulso $\mathbf{O}_{2}$, mL.bat $^{-1}$ & $\begin{array}{c}10 \\
{[7,12]}\end{array}$ & $\begin{array}{c}9 \\
{[8,14]}\end{array}$ & $\begin{array}{c}10 \\
{[9,11]}\end{array}$ & $\begin{array}{c}10 \\
{[8,12]}\end{array}$ & $\begin{array}{c}10 \\
{[9,11]}\end{array}$ & $\begin{array}{c}9 \\
{[8,12]}\end{array}$ \\
\hline Carga pico, W & $\begin{array}{c}54 \\
{[46,89]}\end{array}$ & $\begin{array}{c}70 \\
{[58,109]}\end{array}$ & $\begin{array}{c}62 \\
{[50,89]}\end{array}$ & $\begin{array}{c}72 \\
{[60,120]}\end{array}$ & $\begin{array}{c}58 \\
{[50,70]}\end{array}$ & $\begin{array}{c}57 \\
{[54,65]}\end{array}$ \\
\hline $\mathrm{V} \mathrm{O}_{2} \mathrm{LA}, \mathrm{mL} \cdot \mathrm{kg}^{-1} \cdot \mathrm{min}^{-2}$ & $\begin{array}{c}8,3 \\
{[7,4,9,6]}\end{array}$ & $\begin{array}{c}9,4 \\
{[7,9,11,2]}\end{array}$ & $\begin{array}{c}9,6 \\
{[6,7,10,8]}\end{array}$ & $\begin{array}{c}9,4 \\
{[7,7,10,4]}\end{array}$ & $\begin{array}{c}8,3 \\
{[7,5,9,4]}\end{array}$ & $\begin{array}{c}8,3 \\
{[7,5,9,7]}\end{array}$ \\
\hline Carga LA, W & $\begin{array}{c}29 \\
{[19,38]}\end{array}$ & $\begin{array}{c}29 \\
{[27,56]}\end{array}$ & {$[21,42]$} & $\begin{array}{c}38 \\
{[30,51]}\end{array}$ & $\begin{array}{c}25 \\
{[17,32]}\end{array}$ & $\begin{array}{c}25 \\
{[20,30]}\end{array}$ \\
\hline VE-VCO${ }_{2}$ slope & $35 \pm 7$ & $33 \pm 7$ & $34 \pm 8$ & $31 \pm 4$ & $36 \pm 8$ & $35 \pm 7$ \\
\hline$\Delta \mathrm{VO}_{2} / \Delta$ carga & $10,7 \pm 2,1$ & $9,7 \pm 3,3$ & $11,7 \pm 3,8$ & $9,1 \pm 3,0$ & $9,8 \pm 3,3$ & $10,4 \pm 2,3$ \\
\hline$V P, n(\%)$ & $0(0 \%)$ & $1(8 \%)$ & $5(36 \%)$ & $3(21 \%)$ & $3(21 \%)$ & $3(21 \%)$ \\
\hline
\end{tabular}

RER - razão de trocas respiratórias; $\mathrm{FC} \mathrm{-} \mathrm{frequência} \mathrm{cardíaca} \mathrm{em} \mathrm{batimentos} \mathrm{por} \mathrm{minuto;} \mathrm{VO}_{2}$ pico - consumo pico de oxigênio; Pulso $\mathrm{O}_{2}-$ pulso de oxigênio; VO $\mathrm{LA}_{2}$ - consumo de oxigênio no limiar anaeróbico; Carga LA - carga no limiar anaeróbico; $\mathrm{VE}-\mathrm{VCO}_{2}$ slope - inclinação da curva de ventilação pela produção de dióxido de carbono; $\Delta \mathrm{VO} \mathrm{O}_{2} / \Delta$ carga inclinação da relação do consumo de oxigênio pela carga; VP - ventilação periódica

${ }^{*}-p<0,05$ para comparação entre os três grupos em 12 semanas; ${ }^{\text {a }}$ - Significativamente diferente na comparação de grupos pareados: $p$ ajustado (Bonferroni) $<0,05$ 


\subsection{Biomarcadores inflamatórios}

A figura 2 mostra os níveis séricos de IL-6 (em escala logarítmica), adiponectina, TNF-alfa e galectina-3 antes e após a intervenção de acordo com o grupo. Não houve diferença significativa nos níveis séricos destes biomarcadores em nenhuma das modalidades de treinamento físico em relação ao grupo controle.
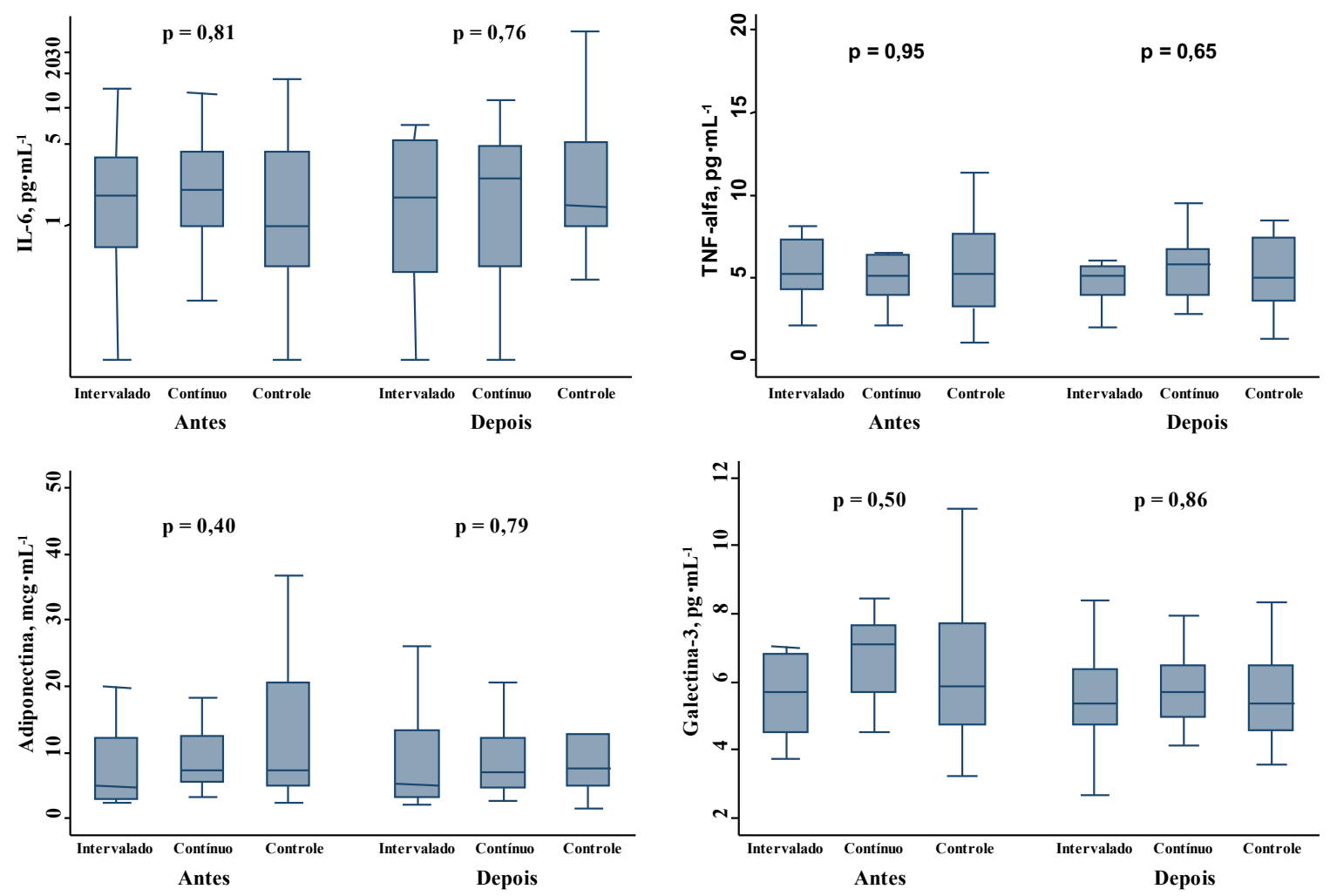

Figura 2: Níveis séricos de interleucina-6 após conversão (A), fator de necrose tumoral-alfa (B), adiponectina (C) e galectina-3 (D) antes e depois da intervenção de acordo com o grupo alocado 


\subsection{MicroRNAs}

A figura 3 mostra a mudança do Cq de cada microRNA circulante de acordo com a intervenção. Como acima descrito, o Cq é inversamente proporcional à expressão, onde a redução em $1 \mathrm{Cq}$ representa um aumento em 2 vezes no número de cópias de microRNA. A variação da expressão dos microRNAs miR-423-5p, -155 e -221 nos pacientes submetidos a exercício intervalado e contínuo foi semelhante a dos pacientes no grupo controle.

miR-423-5p

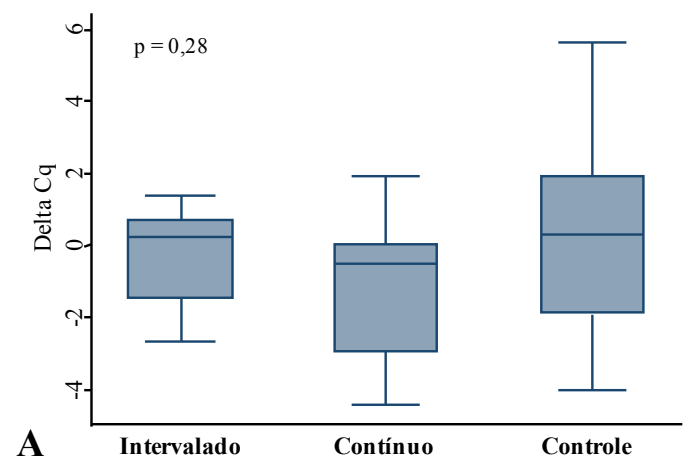

miR-155



miR-221



Figura 3: Mudança nos níveis séricos dos microRNAs miR-423-5p (A), miR-155 (B) e miR-221 (C) de acordo com intervenção realizada de acordo com o grupo alocado.

Delta $\mathrm{Cq}=\mathrm{Cq}_{\text {normalizado }}$ pós $-\mathrm{Cq}_{\text {normalizado }}$ pré intervenção 


\subsection{Qualidade de vida}

As pontuação basais do questionário de qualidade de vida (MLWHF) não diferiram entre os grupos (tabela 3). Após 12 semanas de intervenção, observamos que o exercício intervalado e contínuo reduziram significativamente o escore total, indicando melhor qualidade de vida. Quando as subdimensões foram analisadas separadamente, observamos redução significativa apenas na dimensão física.

Tabela 3: Escore de qualidade de vida de acordo com o questionário Minnesota Living With Heart Failure

\begin{tabular}{lcccc}
\hline Parâmetro & $\begin{array}{c}\text { Intervalado } \\
\mathbf{n = 1 2}\end{array}$ & $\begin{array}{c}\text { Contínuo } \\
\mathbf{n = 1 4}\end{array}$ & $\begin{array}{c}\text { Controle } \\
\mathbf{n}=\mathbf{1 4}\end{array}$ & $\boldsymbol{p}$ \\
\hline BASAL & & & & \\
Escore total & $46[20,58]$ & $31[15,45]$ & $34[21,47]$ & 0,58 \\
Dimensão física & $21[7,26]$ & $13[5,20]$ & $18[13,21]$ & 0,47 \\
Dimensão emocional & $9[5,13]$ & $7[3,12]$ & $4[3,12]$ & 0,44 \\
APÓS INTERVENÇÃo & & & & \\
Escore total & $12[10,18]$ & $18[8,24]$ & $37[21,47]$ & 0,012 \\
Dimensão física & $6[4,9]$ & $8[2,11]$ & $16[10,27]$ & 0,016 \\
Dimensão emocional & $3[1,5]$ & $3[1,7]$ & $6[4,9]$ & 0,12 \\
\hline
\end{tabular}




\subsection{Preditores de resposta ao treinamento físico}

A tabela 4 mostra a análise univariada da associação entre variáveis basais a mudança do $\mathrm{VO}_{2}$ pico com o treinamento físico. Dentre as variáveis do TECP, o tempo de esforço no teste basal associou-se negativamente com a mudança do $\mathrm{VO}_{2}$ pico. Vale notar que as outras variáveis do TECP basal, como o $\mathrm{VO}_{2}$ pico e o RER pico, não foram significativamente associados a resposta ao treinamento.

Nenhum dos parâmetros de avaliação da AFVD basal, como percentual de tempo sedentário, número de passos, intensidade de movimento ou GEA, foram associados com a mudança da capacidade funcional no exercício.

Quanto aos biomarcadores de inflamação e fibrose, os níveis basais de IL-6 correlacionaram-se negativamente com a resposta ao treinamento. Os níveis de galectina-3, adiponectina e de TNF-alfa não tiveram associação significativa com a mudança do $\mathrm{VO}_{2}$ pico. Da mesma forma, a expressão sérica basal dos microRNAs miR-423-5p, -155 e -221 não foi preditor de resposta ao exercício.

À análise multivariada, a IL-6 foi independentemente associada com mudança no $\mathrm{VO}_{2}$ pico após o treinamento físico em pacientes com IC (tabela 5). 
Tabela 4: Associação entre as características basais e a mudança do consumo pico de oxigênio com exercício $(\mathrm{n}=26)$

\begin{tabular}{|c|c|c|c|}
\hline Variável & $\mathbf{R}$ & Coeficiente $\beta \pm \mathrm{SE}$ & $p$ \\
\hline Idade, anos & 0,11 & $0,01 \pm 0,03$ & 0,61 \\
\hline Sexo masculino & $-0,09$ & $-0,17 \pm 0,40$ & 0,68 \\
\hline IMC, Kg.m ${ }^{-2}$ & 0,02 & $0,01 \pm 0,05$ & 0,91 \\
\hline Hipertensão arterial & $-0,25$ & $-0,50 \pm 0,39$ & 0,21 \\
\hline Diabete melito & $-0,24$ & $-0,60 \pm 0,49$ & 0,23 \\
\hline FEVE, \% & 0,28 & $0,05 \pm 0,03$ & 0,17 \\
\hline Etiologia isquêmica & 0,08 & $0,16 \pm 0,43$ & 0,72 \\
\hline \multicolumn{4}{|c|}{ Teste de esforço cardiopulmonar } \\
\hline $\mathrm{VO}_{2}$ pico, \% & $-0,22$ & $-0,02 \pm 0,02$ & 0,28 \\
\hline Tempo de exercício, min & $-0,47$ & $-0,21 \pm 0,08$ & 0,015 \\
\hline RER pico & 0,15 & $1,55 \pm 2,09$ & 0,46 \\
\hline $\mathrm{VO}_{2} \mathrm{LA}, \mathrm{mL} \cdot \mathrm{kg}^{-1} \cdot \mathrm{min}^{-2}$ & $-0,21$ & $-0,07 \pm 0,07$ & 0,32 \\
\hline VE-VCO 2 slope & $-0,04$ & $-0,01 \pm 0,03$ & 0,85 \\
\hline VP & $-0,10$ & $-0,24 \pm 0,51$ & 0,64 \\
\hline \multicolumn{4}{|c|}{ Atividade física na vida diária } \\
\hline Tempo sedentário, \% & $-0,18$ & $-0,02 \pm 0,02$ & 0,37 \\
\hline Passos, $n$ & $-0,05$ & $-0,00 \pm 0,0001$ & 0,80 \\
\hline IM, $\mathbf{g}$ & 0,14 & $4,84 \pm 7,05$ & 0,50 \\
\hline GEA, Kcal* & $-0,01$ & $0,00 \pm 0,001$ & 0,95 \\
\hline \multicolumn{4}{|l|}{ Biomarcadores } \\
\hline Adiponectina, mcg.mL $L^{-1}$ & $-0,04$ & $-0,00 \pm 0,02$ & 0,84 \\
\hline Galectina-3, ng.mL $\mathbf{L}^{-1}$ & $-0,34$ & $-0,17 \pm 0,09$ & 0,087 \\
\hline Log-IL-6, pg.mL $\mathbf{L}^{-1}$ & $-0,56$ & $-0,41 \pm 0,12$ & 0,003 \\
\hline TNF-alfa, pg.mL $\mathbf{L}^{-1}$ & $-0,19$ & $-0,09 \pm 0,09$ & 0,35 \\
\hline miR-423-5p, Cq & 0,16 & $0,12 \pm 0,15$ & 0,44 \\
\hline miR-155, Cq & 0,28 & $0,08 \pm 0,06$ & 0,17 \\
\hline miR-221, Cq & 0,11 & $0,08 \pm 0,15$ & 0,60 \\
\hline Grupo intervalado & $-0,20$ & $0,40 \pm 0,39$ & 0,32 \\
\hline
\end{tabular}

Coeficiente $\beta$ representa a variação do preditor para cada 1 desvio padrão na variável dependente (mudança no $\mathrm{VO}_{2}$ pico).

IMC - índice de massa corpórea; FEVE - fração de ejeção do ventrículo esquerdo; $\mathrm{VO}_{2}$ pico - consumo pico de oxigênio; RER - razão de trocas respiratórias; $\mathrm{VO}_{2}$ LA - consumo de oxigênio no limiar anaeróbico; VE$\mathrm{VCO}_{2}$ slope - inclinação da curva de ventilação pela produção de dióxido de carbono; VP - ventilação periódica; IM - intensidade de movimento em g; GEA - gasto energético durante atividade em quilocalorias; Carga LA - carga no limiar anaeróbico; Log-IL-6 -interleucina-6 após conversão logarítmica; TNF-alfa fator de necrose tumoral alfa; $\mathrm{miR}$ - microRNA; $\mathrm{Cq}$ - cycle quantification 
Tabela 5: Análise de regressão multivariada predizendo a mudança do consumo pico de oxigênio com exercício $(\mathrm{n}=26)$

\begin{tabular}{lccc}
\hline Variável & R parcial & Coeficiente $\boldsymbol{\beta} \pm \mathbf{S E}$ & $\boldsymbol{p}$ \\
\hline Tempo de exercício, min & & & \\
Galectina-3, ng.mL & $-0,39$ & $-0,14 \pm 0,07$ & 0,066 \\
Log IL-6, pg.mL & $-0,38$ & $-0,14 \pm 0,07$ & 0,069 \\
\hline
\end{tabular}

Coeficiente $\beta$ representa a variação do preditor para cada 1 desvio padrão na variável dependente (mudança no VO2 pico) ajustada as demais variáveis do modelo

Log-IL-6 - interleucina-6 após conversão logarítmica 
Discussão 


\section{DISCUSSÃO}

Nosso estudo demostrou que o exercício físico, tanto no modo intervalado como contínuo, tem efeito neutro nos biomarcadores séricos de inflamação e fibrose e nos microRNAs circulantes em pacientes com IC. Além disso, nós observamos que os níveis séricos de IL-6 se associam negativamente à melhora do $\mathrm{VO}_{2}$ pico com exercício nesta população. Este é o primeiro estudo a associar inflamação sistêmica com ausência de melhora na capacidade aeróbica com exercício. Estes resultados foram observados em pacientes já recebendo terapia otimizada para IC, conforme as diretrizes atuais.

\subsection{Efeitos do exercício nos biomarcadores inflamatórios}

Estudos prévios exploraram a influencia do exercício nos biomarcadores inflamatórios em indivíduos saudáveis. Parece haver uma "resposta de fase aguda" em que biomarcadores inflamatórios, incluindo a proteína C reativa e IL-6, aumentam logo após o exercício extenuante e retornam ao basal após alguns dias. ${ }^{50} \mathrm{O}$ músculo exercitado é uma das fontes de IL-6, a qual acumula no sangue em proporção a intensidade, duração e massa de músculo recrutado no exercício. Ao contrário do que seria esperado, os mecanismos de produção de citocina são independentes da existência de injúria muscular, conforme análise da expressão genética local. ${ }^{50}$ Quanto ao exercício físico crônico, estudos prospectivos observaram que os níveis circulantes de biomarcadores inflamatórios reduzem após três meses de treinamento físico em indivíduos saudáveis e em pacientes com claudicação intermitente e diabetes. ${ }^{51-53}$

Em pacientes com IC, estudos prévios observaram ausência de mudança nestes biomarcadores em concordância com nossos achados. Ahmad et al mostrou que níveis sanguíneos de proteína $\mathrm{C}$ reativa permanecem estáveis após exercício de intensidade moderada, mesmo levando em consideração o volume de treinamento. ${ }^{54}$ Gielen et al demonstrou que o treinamento físico não alterou os níveis séricos de IL-6 e TNF-alfa, embora tenha reduzido sua expressão muscular. ${ }^{22} \mathrm{O}$ que ainda era desconhecido é se o 
exercício mais intenso poderia aumentar a inflamação a longo prazo, já que a intensidade está positivamente associada a quantidade de liberação aguda de citocina na circulação. Nossos resultados demonstraram que 12 semanas de exercício intervalado, com curtos períodos de alta intensidade de maneira intermitente, tem efeito neutro nos biomarcadores inflamatórios.

\subsection{Efeito do exercício na qualidade de vida}

O exercício físico, independentemente da modalidade do treino, melhorou a qualidade de vida em três meses de intervenção. Em concordância, no estudo HF-ACTION, o exercício melhorou o estado de saúde medido pelo Kansas City Cardiomyopathy Questionnaire, apesar do efeito discreto no $\mathrm{VO}_{2}$ pico. ${ }^{5}$ Todas as subescalas deste questionário melhoraram com exercício, incluindo qualidade de vida e limitação física. Da mesma forma, observamos melhora na dimensão física do questionário MLWHF. Os grupos intervalado e contínuo também apresentaram melhora (redução) na dimensão emocional da qualidade de vida, mas este resultado não foi estatisticamente significativo possivelmente pelo menor número de questões neste domínio.

É intrigante o fato de termos encontrado melhora na qualidade de vida na ausência de melhora de parâmetros do teste cardiopulmonar associadas com a sensação de dispnéia para as atividades habituais, como $\mathrm{VO}_{2} \mathrm{LA}$, o $\mathrm{VE}-\mathrm{VCO}_{2}$ slope e a ventilação periódica. É possível que os pacientes tenham adquirido maior eficiência biomecânica com o treinamento, resultando em menor $\mathrm{VO}_{2}$ para realizar a mesma atividade. Isto é reforçado pelo maior tempo de tolerância ao exercício no TECP no grupo intervalado, embora a carga pico não tenha apresentado diferença estatisticamente significativa. Outra possiblidade é que a percepção de melhor qualidade de vida possa ter vindo de benefícios além do exercício em si, como engajamento em grupo e maior suporte social. ${ }^{55}$ 


\subsection{MicroRNAs}

Em nosso conhecimento, nosso estudo é o primeiro a avaliar o efeito do exercício físico em microRNAs circulantes em pacientes com IC. Dentre suas propriedades, os microRNAs são secretados na circulação em exosomos, sendo capazes de agir em outras células, em tecido receptor distante de onde é produzido, e modificar a expressão

proteica. $^{56-58}$ Com isso, os microRNAs circulantes podem ajudar a compreender os processos adaptativos ao exercício. ${ }^{9}$

O miR-423-5p é um biomarcador de IC, estando elevado no sangue periférico em comparação com indivíduos saudáveis. Seus níveis circulantes podem indicar gravidade, já que se associam com a classe funcional e níveis séricos de BNP. ${ }^{12,13,59}$ Estudos tem sugerido que os altos níveis circulantes do miR-423-5p provenham do miocárdio. Goldraich et al observaram que o gradiente transcoronário do miR-423-5p é significativamente maior em pacientes com IC em comparação com indivíduos controle, sugerindo que o coração aumenta sua produção na IC sistólica. ${ }^{60}$ De fato, Thum et al observaram que a expressão de miR-423-5p está aumentada no miocárdio do coração explantado de pacientes submetidos a transplante cardíaco. ${ }^{61}$ Em conjunto com outros microRNAs também superexpressos, postula-se que ele possa contribuir para a reprogramação genética do coração em falência resultando em um padrão de expressão semelhante ao coração fetal.

Se assumirmos que os níveis circulantes referem a expressão miocárdica local, nossos resultados sugerem que o exercício não modifica a superexpressão de miR-423-5p e potencialmente não reverteria este padrão anormal de expressão genética no coração. Podendo estar de acordo com estes achados, o exercício intervalado não parece melhorar

a FEVE em pacientes com IC. ${ }^{34}$ Por outro lado, o mecanismo de liberação do miR-423-5p na circulação ainda é incerto, não sendo possível afirmar se decorre da expressão miocárdica aumentada e consequente liberação na corrente sanguínea ou se há outros mecanismos envolvidos, como injúria do miocárdio. Ainda, desconhece-se a razão pela qual os outros microRNAs altamente expressos no coração em falência não estão também elevados no sangue. ${ }^{61}$ 
O miR-155 está envolvido na regulação imune e supressão da oncogênese, embora estes efeitos não tenham sido demonstrados especificamente em pacientes com IC. ${ }^{47}$ Entre diversas vias de sinalização envolvidas, o miR-155 regula positivamente citocinas pró-inflamatórias em macrófagos e células dendríticas. Nossos achados reforçam que o exercício tem impacto neutro na inflamação, como já discutido acima.

Em pacientes com IC, também foi demonstrado que o miR-155 pode suprimir a expressão do gene relacionado ao receptor da angiotensina II do tipo I. ${ }^{48}$ Como a hiperexpressão deste gene está associada com piora da função endotelial, a ação do miR-155 poderia mitigá-la. Embora estudos prévios tenham mostrado efeitos benéficos do exercício na função endotelial na $\mathrm{IC}^{62}{ }^{62}$ a variação da expressão do miR-155 circulante com exercício foi indiferente do controle em nosso estudo. Isto não indica ou afasta, entretanto, que o miR-155 esteja diretamente implicado na função endotelial.

Em contraste com o que encontramos em pacientes com IC, Baggish et al observaram aumento do miR-221 circulante após 90 dias de "treinamento sustentado" em atletas jovens. ${ }^{10}$ Diferenças no desenho e na população estudada podem explicar esta discrepância. Em vista da ausência de grupo controle no estudo de Baggish et al, fatores outros que não o exercício podem ter influenciado seus resultados. Por outro lado, pode ser que processos adaptativos que ocorrem em indivíduos saudáveis não incidem da mesma maneira em pacientes com IC. O miR-221 é altamente expresso nas células endoteliais e pode afetar as propriedades angiogênicas do endotélio. ${ }^{45,46}$ Enquanto há evidência consistente de que o exercício tem efeitos benéficos nas células angiogênicas circulantes (CAC) em indivíduos saudáveis, há poucos estudos em outras populações. ${ }^{63}$ Van Craenenbroeck et al demonstraram que uma sessão de exercício reverte a disfunção de CAC em pacientes com IC. ${ }^{62}$ Eleuteri et al observaram aumento dos níveis sanguíneos de células progenitoras endoteliais após 3 meses de treinamento em pacientes com IC. ${ }^{64}$ Futuros estudos devem avaliar se o miR-221 está implicado no processo adaptativo que envolve o estímulo da angiogênese em pacientes com IC. 


\subsection{Preditores de resposta ao exercício}

Estudos prévios encontraram associação entre alguns biomarcadores séricos e melhora na capacidade funcional com exercício. Ahmad et al classificou pacientes com IC em quatro diferentes fenótipos, através de cluster analysis no estudo HF-ACTION. ${ }^{32}$ Tais fenótipos diferiram entre si em relação ao efeito do exercício na mortalidade e hospitalização por IC. Nesse estudo, o subgrupo que apresentou o maior aumento no $\mathrm{VO}_{2}$ pico tinha os menores níveis basais de galectina-3. Embora não significativa estatisticamente, nós também encontramos uma associação inversa entre níveis séricos de galectina-3 e resposta ao exercício. Por outro lado, a IL-6 foi o único biomarcador independentemente associado com resposta ao exercício. Embora intrinsicamente relacionadas, inflamação precede fibrose biologicamente e a primeira pode ser mais intimamente relacionada as alterações fisiopatológicas que impedem o incremento no transporte e utilização de oxigênio durante o exercício.

Os mecanismos responsáveis pela associação entre níveis de IL-6 e resposta ao exercício é desconhecida. É concebível que IL-6 seja apenas um marcador de gravidade sem participação direta na inibição do aumento do $\mathrm{VO}_{2}$ pico. Estudos anteriores revelaram que níveis circulantes elevados de IL-6, entre outros marcadores de inflamação, estão associados com reduzida capacidade funcional e maior mortalidade em IC. ${ }^{17,54,65,66}$ Embora ainda assunto em debate, anormalidades da mucosa intestinal, ativação do sistema renina-angiotensina-aldosterona e atividade simpática elevada foram implicadas na causa da inflamação em pacientes com IC. ${ }^{66,67}$ Ativação neuro-hormonal excessiva, que ocorrem em pacientes com IC mais avançada, poderia neutralizar as alterações dependentes do endotélio no fluxo sanguíneo periférico, inibindo o aumento no $\mathrm{VO}_{2}$ pico. No entanto, os resultados do estudo HF-ACTION enfraquecem esta hipótese, já que os pacientes com doença mais avançada se beneficiaram mais com exercício do que aqueles com formas mais leves. ${ }^{32}$

Outra teoria é que os efeitos da IL-6 poderiam causar diretamente as anormalidades que impedem a melhora no $\mathrm{VO}_{2}$ pico com exercício. A IL-6 age através de transdução de sinal por unidade receptora transmembrana da glicoproteína 130, causando efeitos no 
sistema cardiovascular. ${ }^{66}$ Estes incluem hipertrofia e apoptose do cardiomiócito, alterações na expressão da matrix metaloproteinase, anormalidades na homeostase de cálcio intracelular do miocárdio, disfunção endotelial, redução na atividade mitocondrial e apoptose do músculo esquelético. Estas consequências poderiam ser tão extremas, que se tornariam irreversíveis com exercício. Além disso, a atividade pro-inflamatória aguda induzida por cada sessão de exercício poderia ser prejudicial naqueles pacientes com um grau elevado de inflamação crônica.

A ausência de impacto na mortalidade no contexto da terapia moderna para IC tem estimulado a procura de subgrupos que possam ter benefício. Como já apontado, a ausência de melhora no $\mathrm{VO}_{2}$ pico com treinamento físico é relacionada a sobrevida. ${ }^{6}$ Mesmo embora causalidade reversa possa estar implicada nesta relação, isto é, os pacientes mais graves são menos aderentes e consequentemente exibiriam menor ganho no $\mathrm{VO}_{2}$ pico, parece que intensidade e volume de treinamento não explicam totalmente esta resposta. Nós demonstramos que níveis de IL-6 prediz resposta ao exercício entre os pacientes que completaram 12 semanas de um programa de supervisão direta, com um mínimo de $70 \%$ de aderência. Além disso, treinamento aeróbico intervalado não influenciou a melhora do $\mathrm{VO}_{2}$ pico. Nossos resultados indicam que fatores relacionados ao paciente estão associados a resposta ao exercício, além do volume e intensidade de treinamento.

\subsection{Limitações}

A taxa de desistência em nosso estudo foi elevada, o que pode ter mitigado a comparabilidade entre os grupos. Embora a análise do tipo "intenção de tratar" seria ideal para preservar os princípios da randomização, o tipo de desfecho neste estudo requer a análise somente dos pacientes que fossem capazes de completar o estudo, ou pelo menos submetidos ao um segundo TECP. Além disso, não houve diferença significativa nas características basais entre os três grupos, indicando que eles permaneceram semelhantes. 
Nós observamos que o tempo de exercício no TECP basal foi inversamente associado a resposta ao treinamento. É possível que este fenômeno tenha subestimado o $\mathrm{VO}_{2}$ pico, amplificando a diferença entre as avaliações pré e pós na ausência de real melhora fisiológica. No entanto, cada participante foi submetido ao mesmo incremento de carga em ambas avaliações e o RER pico foi semelhante entre os respondedores e os não respondedores, sugerindo nível de esforço semelhante. 


\section{Conclusões}




\section{CONCLUSÕES}

Nós concluímos que:

$>\quad \mathrm{O}$ exercício aeróbico, seja intervalado ou contínuo, por 12 semanas teve efeito neutro nos biomarcadores de inflamação e fibrose e nos níveis circulantes dos microRNAs miR-423-5p, -221 e -155 em pacientes com IC.

$>\quad$ O nível sérico de IL-6 é preditor independente de resposta ao treinamento físico em IC. Níveis elevados deste biomarcador estão associados ausência de melhora da capacidade funcional com o exercício.

$>$ Em pacientes com IC, o exercício físico, particularmente intervalado, resultou em melhor qualidade de vida, apesar da ausência de efeito na capacidade funcional. 
Anexos 


\section{ANEXOS}

\subsection{Anexo I}

HOSPITAL DAS CLÍNICAS DA FACULDADE DE MEDICINA DA UNIVERSIDADE DE SÃO PAULO-HCFMUSP

TERMO DE CONSENTIMENTO LIVRE E ESCLARECIDO

DADOS DE IDENTIFICAÇÃO DO SUJEITO DA PESQUISA OU RESPONSÁVEL LEGAL

1. NOME:

DOCUMENTO DE IDENTIDADE $\mathrm{N}^{\circ}$ : SEXO :.$M \square \quad F \quad \square$

DATA NASCIMENTO: .......................

ENDEREÇO

$\mathrm{N}^{\mathrm{o}}$

APTO:

BAIRRO: CIDADE

CEP: TELEFONE: DDD

.)

2.RESPONSÁVEL LEGAL

NATUREZA (grau de parentesco, tutor, curador etc.)

DOCUMENTO DE IDENTIDADE SEXO: $M \square \mathrm{F} \square$

DATA NASCIMENTO.:

ENDEREÇO:

$\mathrm{N}^{\mathrm{o}}$. APTO:

BAIRRO:

CIDADE:

CEP: TELEFONE: DDD ( ..).........

\section{DADOS SOBRE A PESQUISA}

1. TÍTULO DO PROTOCOLO DE PESQUISA: TREINAMENTO INTERVALADO VERSUS TREINAMENTO CONTÍNUO NA ATIVIDADE SIMPÁTICA E PERFUSÃO PERIFÉRICA EM PORTADORES DE INSUFICIÊNCIA CARDÍACA: ESTUDO RANDOMIZADO COM GRUPO CONTROLE.

PESQUISADOR : Jean Marcelo Roque

CARGO/FUNÇÃO: Fisioterapeuta INSCRIÇÃO CONSELHO REGIONAL Nº Crefito-3 74341-F..

UNIDADE DO HCFMUSP: Unidade Clínica de Insuficiência cardíaca.

2. AVALIAÇÃO DO RISCO DA PESQUISA:

$\begin{array}{ccc}\text { RISCO MÍNIMO } & \mathbf{x} & \text { RISCO MÉDIO } \\ \text { RISCO BAIXO } & \square & \text { RISCO MAIOR }\end{array}$

3.DURAÇÃO DA PESQUISA : Três anos 


\section{HOSPITAL DAS CLÍNICAS DA FACULDADE DE MEDICINA DA UNIVERSIDADE DE SÃO PAULO-HCFMUSP}

1. Os médicos diagnosticaram que seu coração aumentou de tamanho, com isso o senhor (a) passou a ter uma doença cardíaca. Essa doença deixa de oxigenar bem o corpo e também os músculos, principalmente durante algumas atividades diárias. Para o senhor (a) que faz parte desse ambulatório, que segue as recomendações dos médicos que o atendem, estamos também disponibilizando um programa de atividade física para melhorar sua condição física, resultando em melhor qualidade de vida. Estudos demonstraram os benefícios que a atividade física traz ao seu problema. Estamos iniciando um estudo para mensurar os efeitos do exercício com intensidade variada, avaliando a circulação sanguínea, oxigenação muscular e examinar as células musculares. Desse modo, o exercício a ser realizado poderá também trazer benefícios a sua saúde, melhorando sua qualidade de vida.

2. Caso aceite participar do estudo, será feito sorteio para designar qual atividade física o senhor (a) realizará: exercícios com intensidade variada, isto é, vai caminhar em velocidade lenta e um pouco mais rápida de forma alternada, ou continua sempre na mesma velocidade. $\mathrm{O}$ treino será realizado em esteira rolante por até 60 (sessenta minutos), 3 (três) vezes por semana por um período de 3 (três) meses. Será feita uma avaliação antes e outra após o treinamento. O senhor (a) fará os seguintes exames: 1. Teste cardiopulmonar é utilizado para avaliarmos como está a sua capacidade física. Nesse teste você irá pedalar em uma bicicleta estacionária e será observado como se comporta seu coração e respiração. Em quaisquer sinais de cansaço, tonturas, palpitações e falta de ar, o teste será interrompido; 2. Medição do fluxo sanguíneo e oxigenação muscular através de uma luz apontada para tua coxa; 3 Num outro dia que você vier ao hospital, será realizado o exame do músculo da coxa. Primeiro será feita a limpeza cuidadosa do local para prevenir infecção, depois o local será anestesiado para que você não sinta nenhuma dor e finalmente será feito um pequeno corte na parte lateral da sua coxa e colocada uma agulha apropriada para retirada de um pedaço bem pequeno de músculo, o senhor não ficará com a força prejudicada. Depois disso, será feito um curativo no local. Esse exame será feito por um médico bem treinado nessa técnica. Esse exame é muito importante para saber se o exercício melhora a quantidade de músculo na sua perna. 4. Será feita através de uma fina agulha a análise da condução nervosa, de um nervo superficial, ou seja, próximo à pele, que passa abaixo do joelho do lado de fora. Será feita a limpeza local e o procedimento não causara dor, poderá apenas ter a sensação momentânea de um leve choque. 5. Você irá utilizar um aparelho chamado acelerômetro durante vinte e quatro horas durante suas atividades habituais antes e após o programa de treinamento. Este aparelho é uma espécie de cinta de tecido que você vestirá, e nela há um pequeno dispositivo (menor que um aparelho celular). 6. Você será submetido a duas coletas de sangue, através da punção de uma veia periférica, onde serão retirados aproximadamente $8 \mathrm{~mL}$ cada vez. A primeira coleta será realizada antes e a segunda após o treinamento físico.

3. Este tratamento está associado a um risco muito baixo de complicações e desconfortos, uma vez que o senhor realizará exames para podermos indicar com segurança a atividade física. É provável que o senhor (a) se canse um pouco quando realizar o teste cardiopulmonar, caso sinta muito desconforto o teste será interrompido, assim que o teste terminar o desconforto também cessará. No início do programa de treinamento físico, pode ser que o senhor (a) se sinta um pouco mais cansado (a), como qualquer indivíduo que inicie atividade física, pois o corpo não estava acostumado, mas após alguns dias essa sensação deve melhorar, pois já se iniciam os benefícios da prática de atividade física. Outro procedimento que pode causar algum desconforto, é a punção venosa para coleta de sangue em que você pode sentir dor provocada pela picada da agulha. Embora seja pequena a probabilidade, podem ocorrer formação de

Termo de Consentimento Livre e Esclarecido, versão número 4, de 20 de setembro de 2011. 
hematomas e infecção no local da punção. Vale salientar que todos os cuidados serão tomados para evitá-los.

4. Com a realização do programa de exercícios físicos, poderemos melhorar sua capacidade física, baixar os níveis da tua pressão arterial e conhecer bem a irrigação sanguínea muscular e a integridade de seu músculo. Somente no final do estudo é que poderemos concluir a presença de algum benefício esperado ou não. Todos os exames realizados serão usufruídos para melhor ajuste de drogas ou outras terapêuticas necessárias.

5. Em qualquer etapa do estudo, você terá acesso aos profissionais responsáveis pela pesquisa para esclarecimento de eventuais dúvidas. O principal investigador é o Dr Guilherme Veiga Guimarães, que pode ser encontrado no endereço Av. Dr Enéas de Carvalho Aguiar, $44-1^{\circ}$ andar, bloco 1 - tel: 3069-5419. Se você tiver alguma consideração ou dúvida sobre a ética da pesquisa, entre em contato com o Comitê de Ética em Pesquisa (CEP) - Rua Ovídio Pires de Campos, 225 - $5^{\circ}$ andar - tel: 3069-6442 ramais 16, 17, 18 ou 20, FAX: 3069-6442 ramal 26 E-mail:cappesq@hcnet.usp.br

6. É garantida a liberdade da sua retirada de consentimento a qualquer momento e deixar de participar do estudo, sem qualquer prejuízo à continuidade de seu tratamento na Instituição (InCor);

7. As informações obtidas serão analisadas em conjunto com a de outros pacientes, não sendo divulgado a identificação de nenhum de vocês;

8. Quem participar da pesquisa será atualizado sobre os resultados parciais das pesquisas, ou seja, dos achados antes do término da pesquisa.

9. Não há despesas pessoais para o participante em qualquer fase do estudo, incluindo testes, exames e o treinamento. Também não há compensação financeira relacionada à sua participação, haverá se necessário, uma ajuda de custo para o transporte (deslocamento) até a instituição, apenas nos dias de testes e treinamento, sendo a quantia de duas conduções (metrô/ônibus) por dia. Se existir qualquer despesa adicional, ela será absorvida pelo orçamento da pesquisa.

10. O material coletado será acondicionado no banco de materiais biológico da unidade e servirá para futuras pesquisas.

Acredito ter sido suficientemente informado a respeito das informações que li ou que foram lidas para mim, descrevendo o estudo "Treinamento Intervalado Versus Treinamento Contínuo na Atividade Simpática e Perfusão Periféricas em Pacientes Portadores de Insuficiência Cardíaca".

Termo de Consentimento Livre e Esclarecido, versão número 4, de 20 de setembro de 2011. 


\section{HOSPITAL DAS CLÍNICAS DA FACULDADE DE MEDICINA DA UNIVERSIDADE DE SÃOPAULO - HCFMUSP}

Eu discuti com o Dr. Guilherme Veiga Guimarães sobre a minha decisão em participar nesse estudo. Ficaram claros para mim quais são os propósitos do estudo, os procedimentos a serem realizados, seus desconfortos e riscos, as garantias de confidencialidade e de esclarecimentos permanentes. Ficou claro também que minha participação é isenta de despesas e que tenho garantia do acesso a tratamento hospitalar quando necessário. Concordo voluntariamente em participar deste estudo e poderei retirar o meu consentimento a qualquer momento, antes ou durante o mesmo, sem penalidades ou prejuízo ou perda de qualquer benefício que eu possa ter adquirido, ou no meu atendimento neste Serviço.

Assinatura do paciente/representante legal

Data

11

Assinatura da testemunha



para casos de pacientes menores de 18 anos, analfabetos, semi-analfabetos ou portadores de deficiência auditiva ou visual.

(Somente para o responsável do projeto)

Declaro que obtive de forma apropriada e voluntária o Consentimento Livre e Esclarecido deste paciente ou representante legal para a participação neste estudo.

Assinatura do responsável pelo estudo

Data

11

Termo de Consentimento Livre e Esclarecido, versão número 4, de 20 de setembro de 2011. 


\subsection{Anexo II}

\section{QUESTIONÁRIO MINNESOTA LIVING WITH HEART FAILURE*}

Nome:

RG:

As seguintes questões perguntam o quanto a insuficiência cardíaca (sua condição cardíaca) afetou a sua vida durante o último mês (nas últimas 4 semanas). Em cada questão, circule o número 0, 1, 2, 3, 4 ou 5 para mostrar o quanto a sua vida foi afetada. Se a questão não se aplica a você, circule o 0 nesta questão.

\begin{tabular}{|c|c|c|c|c|c|c|}
\hline $\begin{array}{l}\text { Durante o último mês seu problema cardíaco o impediu } \\
\text { de viver como você queria por quê? }\end{array}$ & Não & Muito & & & Iuit & \\
\hline 1. Causou inchaço em seus tornozelos e pernas & $\mathbf{0}$ & 1 & 2 & 3 & 4 & 5 \\
\hline $\begin{array}{l}\text { 2. Obrigando você a se sentar ou deitar para descansar } \\
\text { durante o dia }\end{array}$ & $\mathbf{0}$ & 1 & 2 & 3 & 4 & 5 \\
\hline 3. Tornando sua caminhada e subida de escadas difícil & $\mathbf{0}$ & 1 & 2 & 3 & 4 & 5 \\
\hline 4. Tornando seu trabalho doméstico difícil & $\mathbf{0}$ & 1 & 2 & 3 & 4 & 5 \\
\hline 5. Tornando suas saídas de casa difícil & $\mathbf{0}$ & 1 & 2 & 3 & 4 & 5 \\
\hline 6. Tornando difícil dormir bem à noite & $\mathbf{0}$ & 1 & 2 & 3 & 4 & 5 \\
\hline $\begin{array}{l}\text { 7. Tornando seus relacionamentos ou atividades com } \\
\text { familiares e amigos difícil }\end{array}$ & $\mathbf{0}$ & 1 & 2 & 3 & 4 & 5 \\
\hline 8. Tornando seu trabalho para ganhar a vida difícil & $\mathbf{0}$ & 1 & 2 & 3 & 4 & 5 \\
\hline 9. Tornando seus passatempos, esportes e diversão difícil & $\mathbf{0}$ & 1 & 2 & 3 & 4 & 5 \\
\hline 10. Tornando sua atividade sexual difícil & $\mathbf{0}$ & 1 & 2 & 3 & 4 & 5 \\
\hline 11. Fazendo você comer menos as comidas que você gosta & $\mathbf{0}$ & 1 & 2 & 3 & 4 & 5 \\
\hline 12. Causando falta de ar & $\mathbf{0}$ & 1 & 2 & 3 & 4 & 5 \\
\hline 13. Deixando você cansado, fatigado ou com pouca energia & $\mathbf{0}$ & 1 & 2 & 3 & 4 & 5 \\
\hline 14. Obrigando você a ficar hospitalizado & $\mathbf{0}$ & 1 & 2 & 3 & 4 & 5 \\
\hline 15. Fazendo você gastar dinheiro com cuidados médicos & $\mathbf{0}$ & 1 & 2 & 3 & 4 & 5 \\
\hline 16. Causando a você efeitos colaterais das medicações & $\mathbf{0}$ & 1 & 2 & 3 & 4 & 5 \\
\hline 17. Fazendo você sentir-se um peso para familiares e amigos & $\mathbf{0}$ & 1 & 2 & 3 & 4 & 5 \\
\hline $\begin{array}{l}\text { 18. Fazendo você sentir uma falta de auto controle na sua } \\
\text { vida }\end{array}$ & $\mathbf{0}$ & 1 & 2 & 3 & 4 & 5 \\
\hline 19. Fazendo você se preocupar & $\mathbf{0}$ & 1 & 2 & 3 & 4 & 5 \\
\hline $\begin{array}{l}\text { 20. Tornando difícil você concentrar-se ou lembrar-se das } \\
\text { coisas }\end{array}$ & 0 & 1 & 2 & 3 & 4 & 5 \\
\hline 21. Fazendo você sentir-se deprimido & $\mathbf{0}$ & 1 & 2 & 3 & 4 & 5 \\
\hline
\end{tabular}

* Adaptado de Carvalho et al ${ }^{(59)}$. 
Referências 


\section{REFERÊNCIAS}

1. Bocchi EA, Braga FGM, Ferreira SMA, Rohde LEP, Oliveira WA de, Almeida DR de, Moreira M da CV, Bestetti RB, Bordignon S, Azevedo C, Tinoco EM, Rocha RM, Issa VS, Ferraz A, Cruz F das D, Guimarães GV, Montera VDSP, Albuquerque DC, Bacal F, Souza GEC, Rossi Neto JM, Clausell NO, Martins SM, Siciliano A, Souza Neto JD de, Moreira LF, Teixeira RA, Moura LZ, Beck-da-Silva L, Rassi S, Azeka E, Horowitz E, Ramires F, Simões MV, Castro RBP de, Salemi VMC, Villacorta Junior H, Vila JH, Simões R, Albanesi F, Montera MW, Sociedasde Brasileira de Cardiologia. [III Brazilian Guidelines on Chronic Heart Failure]. Arq Bras Cardiol. 2009;93:3-70.

2. Anker SD, von Haehling S. Inflammatory mediators in chronic heart failure: an overview. Heart Br Card Soc. 2004;90:464-470.

3. Bristow MR, Saxon LA, Boehmer J, Krueger S, Kass DA, De Marco T, Carson P, DiCarlo L, DeMets D, White BG, DeVries DW, Feldman AM, Comparison of Medical Therapy, Pacing, and Defibrillation in Heart Failure (COMPANION) Investigators. Cardiac-resynchronization therapy with or without an implantable defibrillator in advanced chronic heart failure. N Engl J Med. 2004;350:2140-2150.

4. Piña IL, Apstein CS, Balady GJ, Belardinelli R, Chaitman BR, Duscha BD, Fletcher BJ, Fleg JL, Myers JN, Sullivan MJ, American Heart Association Committee on exercise, rehabilitation, and prevention. Exercise and heart failure: A statement from the American Heart Association Committee on exercise, rehabilitation, and prevention. Circulation. 2003;107:1210-1225.

5. Flynn KE, Piña IL, Whellan DJ, Lin L, Blumenthal JA, Ellis SJ, Fine LJ, Howlett JG, Keteyian SJ, Kitzman DW, Kraus WE, Miller NH, Schulman KA, Spertus JA, O'Connor $\mathrm{CM}$, Weinfurt KP, HF-ACTION Investigators. Effects of exercise training on health status in patients with chronic heart failure: HF-ACTION randomized controlled trial. JAMA. 2009;301:1451-1459.

6. Tabet J-Y, Meurin P, Beauvais F, Weber H, Renaud N, Thabut G, Cohen-Solal A, Logeart D, Ben Driss A. Absence of exercise capacity improvement after exercise 
training program: a strong prognostic factor in patients with chronic heart failure. Circ Heart Fail. 2008;1:220-226.

7. Condorelli G, Latronico MVG, Dorn GW. microRNAs in heart disease: putative novel therapeutic targets? Eur Heart J. 2010;31:649-658.

8. Fichtlscherer S, De Rosa S, Fox H, Schwietz T, Fischer A, Liebetrau C, Weber M, Hamm CW, Röxe T, Müller-Ardogan M, Bonauer A, Zeiher AM, Dimmeler S. Circulating microRNAs in patients with coronary artery disease. Circ Res. 2010;107:677-684.

9. Baggish AL, Park J, Min P-K, Isaacs S, Parker BA, Thompson PD, Troyanos C, D'Hemecourt P, Dyer S, Thiel M, Hale A, Chan SY. Rapid upregulation and clearance of distinct circulating microRNAs after prolonged aerobic exercise. J Appl Physiol Bethesda Md 1985. 2014;116:522-531.

10. Baggish AL, Hale A, Weiner RB, Lewis GD, Systrom D, Wang F, Wang TJ, Chan SY. Dynamic regulation of circulating microRNA during acute exhaustive exercise and sustained aerobic exercise training. J Physiol. 2011;589:3983-3994.

11. Fernandes-Silva MM, Carvalho VO, Guimarães GV, Bacal F, Bocchi EA. Physical exercise and microRNAs: new frontiers in heart failure. Arq Bras Cardiol. 2012;98:459466.

12. Tijsen AJ, Creemers EE, Moerland PD, de Windt LJ, van der Wal AC, Kok WE, Pinto YM. MiR423-5p as a circulating biomarker for heart failure. Circ Res. 2010;106:10351039.

13. Goren Y, Kushnir M, Zafrir B, Tabak S, Lewis BS, Amir O. Serum levels of microRNAs in patients with heart failure. Eur J Heart Fail. 2012;14:147-154.

14. Torre-Amione G, Kapadia S, Lee J, Durand JB, Bies RD, Young JB, Mann DL. Tumor necrosis factor-alpha and tumor necrosis factor receptors in the failing human heart. Circulation. 1996;93:704-711. 
15. Adamopoulos S, Parissis JT, Kremastinos DT. A glossary of circulating cytokines in chronic heart failure. Eur J Heart Fail. 2001;3:517-526.

16. Van Kimmenade RRJ, Januzzi JL. Emerging biomarkers in heart failure. Clin Chem. 2012;58:127-138.

17. Tsutamoto T, Hisanaga T, Wada A, Maeda K, Ohnishi M, Fukai D, Mabuchi N, Sawaki M, Kinoshita M. Interleukin-6 spillover in the peripheral circulation increases with the severity of heart failure, and the high plasma level of interleukin- 6 is an important prognostic predictor in patients with congestive heart failure. J Am Coll Cardiol. 1998;31:391-398.

18. Torre-Amione G, Kapadia S, Benedict C, Oral H, Young JB, Mann DL. Proinflammatory cytokine levels in patients with depressed left ventricular ejection fraction: a report from the Studies of Left Ventricular Dysfunction (SOLVD). J Am Coll Cardiol. 1996;27:12011206.

19. Toth MJ, Ades PA, Tischler MD, Tracy RP, LeWinter MM. Immune activation is associated with reduced skeletal muscle mass and physical function in chronic heart failure. Int J Cardiol. 2006;109:179-187.

20. Niebauer J. Effects of exercise training on inflammatory markers in patients with heart failure. Heart Fail Rev. 2008;13:39-49.

21. Conraads VM, Beckers P, Bosmans J, De Clerck LS, Stevens WJ, Vrints CJ, Brutsaert DL. Combined endurance/resistance training reduces plasma TNF-alpha receptor levels in patients with chronic heart failure and coronary artery disease. Eur Heart $J$. 2002;23:1854-1860.

22. Gielen S, Adams V, Möbius-Winkler S, Linke A, Erbs S, Yu J, Kempf W, Schubert A, Schuler G, Hambrecht R. Anti-inflammatory effects of exercise training in the skeletal muscle of patients with chronic heart failure. J Am Coll Cardiol. 2003;42:861-868.

23. Simpson KA, Singh MAF. Effects of exercise on adiponectin: a systematic review. Obes Silver Spring Md. 2008;16:241-256. 
24. Kistorp C, Faber J, Galatius S, Gustafsson F, Frystyk J, Flyvbjerg A, Hildebrandt P. Plasma adiponectin, body mass index, and mortality in patients with chronic heart failure. Circulation. 2005;112:1756-1762.

25. Sharma UC, Pokharel S, van Brakel TJ, van Berlo JH, Cleutjens JPM, Schroen B, André S, Crijns HJGM, Gabius H-J, Maessen J, Pinto YM. Galectin-3 marks activated macrophages in failure-prone hypertrophied hearts and contributes to cardiac dysfunction. Circulation. 2004;110:3121-3128.

26. van Kimmenade RR, Januzzi JL, Ellinor PT, Sharma UC, Bakker JA, Low AF, Martinez A, Crijns HJ, MacRae CA, Menheere PP, Pinto YM. Utility of amino-terminal pro-brain natriuretic peptide, galectin-3, and apelin for the evaluation of patients with acute heart failure. J Am Coll Cardiol. 2006;48:1217-1224.

27. Lok DJ, Lok SI, Bruggink-André de la Porte PW, Badings E, Lipsic E, van Wijngaarden J, de Boer RA, van Veldhuisen DJ, van der Meer P. Galectin-3 is an independent marker for ventricular remodeling and mortality in patients with chronic heart failure. Clin Res Cardiol. 2013;102:103-110.

28. Felker GM, Fiuzat M, Shaw LK, Clare R, Whellan DJ, Bettari L, Shirolkar SC, Donahue M, Kitzman DW, Zannad F, Piña IL, O'Connor CM. Galectin-3 in ambulatory patients with heart failure: results from the HF-ACTION study. Circ Heart Fail. 2012;5:72-78.

29. Ahmad T, Fiuzat M, Neely B, Neely ML, Pencina MJ, Kraus WE, Zannad F, Whellan DJ, Donahue MP, Piña IL, Adams KF, Kitzman DW, O'Connor CM, Felker GM. Biomarkers of myocardial stress and fibrosis as predictors of mode of death in patients with chronic heart failure. JACC Heart Fail. 2014;2:260-268.

30. Gullestad L, Ueland T, Kjekshus J, Nymo SH, Hulthe J, Muntendam P, Adourian A, Böhm M, van Veldhuisen DJ, Komajda M, Cleland JGF, Wikstrand J, McMurray JJV, Aukrust P, CORONA Study Group. Galectin-3 predicts response to statin therapy in the Controlled Rosuvastatin Multinational Trial in Heart Failure (CORONA). Eur Heart J. 2012;33:2290-2296. 
31. Anand IS, Rector TS, Kuskowski M, Adourian A, Muntendam P, Cohn JN. Baseline and serial measurements of galectin-3 in patients with heart failure: relationship to prognosis and effect of treatment with valsartan in the Val-HeFT. Eur J Heart Fail. 2013;15:511518.

32. Ahmad T, Pencina MJ, Schulte PJ, O’Brien E, Whellan DJ, Piña IL, Kitzman DW, Lee KL, O'Connor CM, Felker GM. Clinical implications of chronic heart failure phenotypes defined by cluster analysis. J Am Coll Cardiol. 2014;64:1765-1774.

33. Wisløff U, Støylen A, Loennechen JP, Bruvold M, Rognmo Ø, Haram PM, Tjønna AE, Helgerud J, Slørdahl SA, Lee SJ, Videm V, Bye A, Smith GL, Najjar SM, Ellingsen Ø, Skjaerpe T. Superior cardiovascular effect of aerobic interval training versus moderate continuous training in heart failure patients: a randomized study. Circulation. 2007;115:3086-3094.

34. Haykowsky MJ, Timmons MP, Kruger C, McNeely M, Taylor DA, Clark AM. Metaanalysis of aerobic interval training on exercise capacity and systolic function in patients with heart failure and reduced ejection fractions. Am J Cardiol. 2013;111:1466-1469.

35. Walsh JT, Charlesworth A, Andrews R, Hawkins M, Cowley AJ. Relation of daily activity levels in patients with chronic heart failure to long-term prognosis. Am J Cardiol. 1997;79:1364-1369.

36. Meneghelo RS, Araújo CGS, Stein R, Mastrocolla LE, Albuquerque PF, Serra SM et al/Sociedade Brasileira de Cardiologia. III Diretrizes da Sociedade Brasileira de Cardiologia sobre Teste Ergométrico. Arq Bras Cardiol 2010; 95(5 supl.1): 1-26.

37. Wasserman K, Sue D, Stringer W, Whipp B. Normal values. In: Principles of exercise testing and interpretation. Philadelphia: Lippincott Williams \& Wilkins; 2005. p. 160-168.

38. Gitt AK, Wasserman K, Kilkowski C, Kleemann T, Kilkowski A, Bangert M, Schneider S, Schwarz A, Senges J. Exercise anaerobic threshold and ventilatory efficiency identify heart failure patients for high risk of early death. Circulation. 2002;106:3079-3084. 
39. Leite JJ, Mansur AJ, de Freitas HFG, Chizola PR, Bocchi EA, Terra-Filho M, Neder JA, Lorenzi-Filho G. Periodic breathing during incremental exercise predicts mortality in patients with chronic heart failure evaluated for cardiac transplantation. J Am Coll Cardiol. 2003;41:2175-2181.

40. Pitta F, Troosters T, Spruit MA, Decramer M, Gosselink R. Activity monitoring for assessment of physical activities in daily life in patients with chronic obstructive pulmonary disease. Arch Phys Med Rehabil. 2005;86:1979-1985.

41. van Hees VT, van Lummel RC, Westerterp KR. Estimating activity-related energy expenditure under sedentary conditions using a tri-axial seismic accelerometer. Obes Silver Spring Md. 2009;17:1287-1292.

42. Brandes M, VAN Hees VT, Hannöver V, Brage S. Estimating energy expenditure from raw accelerometry in three types of locomotion. Med Sci Sports Exerc. 2012;44:22352242.

43. Rector TS, Cohn JN. Assessment of patient outcome with the Minnesota Living with Heart Failure questionnaire: reliability and validity during a randomized, double-blind, placebo-controlled trial of pimobendan. Pimobendan Multicenter Research Group. Am Heart J. 1992;124:1017-1025.

44. Carvalho VO, Guimarães GV, Carrara D, Bacal F, Bocchi EA. Validation of the Portuguese version of the Minnesota Living with Heart Failure Questionnaire. Arq Bras Cardiol. 2009;93:39-44.

45. Suárez Y, Fernández-Hernando C, Pober JS, Sessa WC. Dicer dependent microRNAs regulate gene expression and functions in human endothelial cells. Circ Res. 2007;100:1164-1173.

46. Kuehbacher A, Urbich C, Zeiher AM, Dimmeler S. Role of Dicer and Drosha for endothelial microRNA expression and angiogenesis. Circ Res. 2007;101:59-68.

47. Mashima R. Physiological roles of miR-155. Immunology. 2015;145:323-333. 
48. Zheng L, Xu C-C, Chen W-D, Shen W-L, Ruan C-C, Zhu L-M, Zhu D-L, Gao P-J. MicroRNA-155 regulates angiotensin II type 1 receptor expression and phenotypic differentiation in vascular adventitial fibroblasts. Biochem Biophys Res Commun. 2010;400:483-488.

49. Kroh EM, Parkin RK, Mitchell PS, Tewari M. Analysis of circulating microRNA biomarkers in plasma and serum using quantitative reverse transcription-PCR (qRTPCR). Methods San Diego Calif. 2010;50:298-301.

50. Pereira DAG, Ribeiro-Samora GA, Vieira DSR, Pereira LSM, Coelho FM, Parreira VF, Moreira M da CV, Alencar MCN, Britto RR. Evaluation of the inflammatory response to two different intensities of exercise in individuals with heart failure. Inflammation. 2012;35:509-515.

51. Tisi PV, Hulse M, Chulakadabba A, Gosling P, Shearman CP. Exercise training for intermittent claudication: does it adversely affect biochemical markers of the exerciseinduced inflammatory response? Eur J Vasc Endovasc Surg Off J Eur Soc Vasc Surg. 1997;14:344-350.

52. Mattusch F, Dufaux B, Heine O, Mertens I, Rost R. Reduction of the plasma concentration of C-reactive protein following nine months of endurance training. Int $J$ Sports Med. 2000;21:21-24.

53. Balducci S, Zanuso S, Nicolucci A, Fernando F, Cavallo S, Cardelli P, Fallucca S, Alessi E, Letizia C, Jimenez A, Fallucca F, Pugliese G. Anti-inflammatory effect of exercise training in subjects with type 2 diabetes and the metabolic syndrome is dependent on exercise modalities and independent of weight loss. Nutr Metab Cardiovasc Dis NMCD. 2010;20:608-617.

54. Ahmad T, Fiuzat M, Mark DB, Neely B, Neely M, Kraus WE, Kitzman DW, Whellan DJ, Donahue M, Zannad F, Piña IL, Adams K, O'Connor CM, Felker GM. The effects of exercise on cardiovascular biomarkers in patients with chronic heart failure. Am Heart J. 2014;167:193-202.e1. 
55. Kanamori S, Kai Y, Kondo K, Hirai H, Ichida Y, Suzuki K, Kawachi I. Participation in sports organizations and the prevention of functional disability in older Japanese: the AGES Cohort Study. PloS One. 2012;7:e51061.

56. Zhang Y, Liu D, Chen X, Li J, Li L, Bian Z, Sun F, Lu J, Yin Y, Cai X, Sun Q, Wang K, Ba Y, Wang Q, Wang D, Yang J, Liu P, Xu T, Yan Q, Zhang J, Zen K, Zhang C-Y. Secreted monocytic miR-150 enhances targeted endothelial cell migration. Mol Cell. 2010;39:133-144.

57. Kosaka N, Iguchi H, Yoshioka Y, Takeshita F, Matsuki Y, Ochiya T. Secretory mechanisms and intercellular transfer of microRNAs in living cells. $J$ Biol Chem. 2010;285:17442-17452.

58. Valadi H, Ekström K, Bossios A, Sjöstrand M, Lee JJ, Lötvall JO. Exosome-mediated transfer of mRNAs and microRNAs is a novel mechanism of genetic exchange between cells. Nat Cell Biol. 2007;9:654-659.

59. Fan K-L, Zhang H-F, Shen J, Zhang Q, Li X-L. Circulating microRNAs levels in Chinese heart failure patients caused by dilated cardiomyopathy. Indian Heart J. 2013;65:12-16.

60. Goldraich LA, Martinelli NC, Matte U, Cohen C, Andrades M, Pimentel M, Biolo A, Clausell N, Rohde LE. Transcoronary gradient of plasma microRNA 423-5p in heart failure: evidence of altered myocardial expression. Biomark Biochem Indic Expo Response Susceptibility Chem. 2014;19:135-141.

61. Thum T, Galuppo P, Wolf C, Fiedler J, Kneitz S, van Laake LW, Doevendans PA, Mummery CL, Borlak J, Haverich A, Gross C, Engelhardt S, Ertl G, Bauersachs J. MicroRNAs in the human heart: a clue to fetal gene reprogramming in heart failure. Circulation. 2007;116:258-267.

62. Van Craenenbroeck EM, Conraads VM. Mending injured endothelium in chronic heart failure: a new target for exercise training. Int J Cardiol. 2013;166:310-314.

63. Witkowski S, Jenkins NT, Hagberg JM. Enhancing treatment for cardiovascular disease: exercise and circulating angiogenic cells. Exerc Sport Sci Rev. 2011;39:93-101. 
64. Eleuteri E, Mezzani A, Di Stefano A, Vallese D, Gnemmi I, Delle Donne L, Taddeo A, Della Bella S, Giannuzzi P. Aerobic training and angiogenesis activation in patients with stable chronic heart failure: a preliminary report. Biomark Biochem Indic Expo Response Susceptibility Chem. 2013;18:418-424.

65. Aukrust P, Ueland T, Lien E, Bendtzen K, Müller F, Andreassen AK, Nordøy I, Aass H, Espevik T, Simonsen S, Frøland SS, Gullestad L. Cytokine network in congestive heart failure secondary to ischemic or idiopathic dilated cardiomyopathy. Am J Cardiol. 1999;83:376-382.

66. Askevold ET, Gullestad L, Dahl CP, Yndestad A, Ueland T, Aukrust P. Interleukin-6 signaling, soluble glycoprotein 130, and inflammation in heart failure. Curr Heart Fail Rep. 2014;11:146-155.

67. Rogler G, Rosano G. The heart and the gut. Eur Heart J. 2014;35:426-430. 